
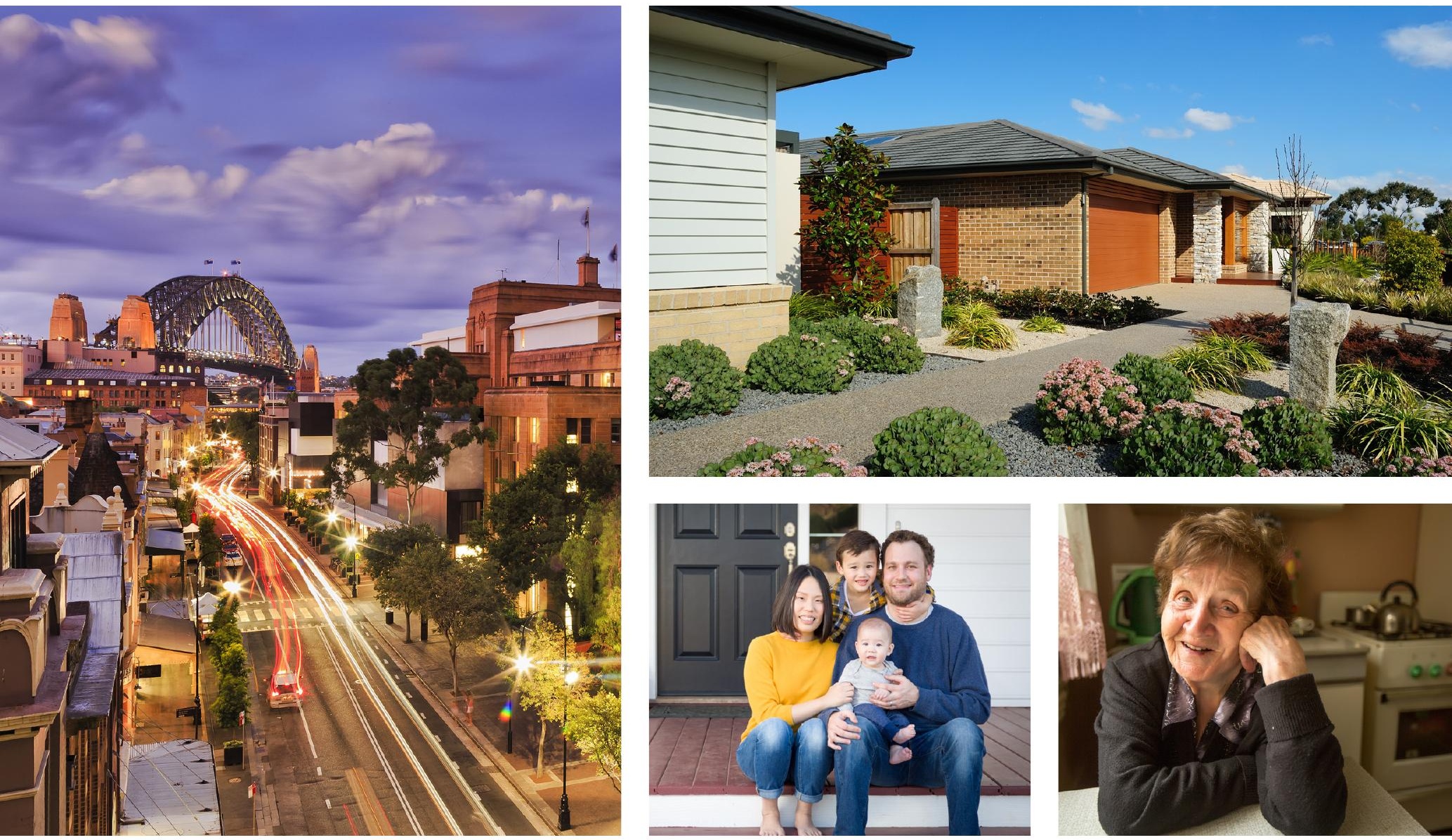

\title{
Improving housing and service responses to domestic and family violence for Indigenous individuals and families
}

From the AHURI Inquiry

Integrated housing support for vulnerable families

\section{FOR THE}

\section{Australian Housing}

and Urban Research Institute

PUBLICATION DATE

August 2019

DOI
AUTHORED BY

Kyllie Cripps

University of New South Wales

Daphne Habibis

University of Tasmania 


\begin{tabular}{lll} 
Title & \multicolumn{1}{l}{$\begin{array}{l}\text { Improving housing and service responses to domestic and family violence for } \\
\text { Indigenous individuals and families }\end{array}$} \\
\hline Authors & Kyllie Cripps & \multicolumn{1}{l}{ University of New South Wales } \\
& Daphne Habibis & University of Tasmania \\
\hline ISBN & $978-1-925334-84-5$ & 320 \\
\hline Key words & $\begin{array}{l}\text { Indigenous domestic and family violence, Indigenous housing outcomes, service } \\
\text { integration, housing pathways }\end{array}$ \\
\hline Series & AHURI Final Report $\quad$ Number \\
\hline Publisher & $\begin{array}{l}\text { Australian Housing and Urban Research Institute Limited } \\
\text { Melbourne, Australia }\end{array}$ \\
\hline DOI & 10.18408/ahuri-7116201 \\
\hline Format & PDF, online only \\
\hline URL & http://www.ahuri.edu.au/research/final-reports/320 \\
\hline
\end{tabular}

\section{Recommended citation}

Cripps, K. and Habibis, D. (2019) Improving housing and service responses to domestic and family violence for Indigenous individuals and families, AHURI Final Report 320, Australian Housing and Urban Research Institute Limited, Melbourne, http://www.ahuri.edu.au/research/final-reports/320, doi: 10.18408/ahuri-7116201.

\section{Related reports and documents}

Integrated housing support for vulnerable families

https://www.ahuri.edu.au/research/research-in-progress/ahuri-inquiries/evidence-based-policyinquiry-71160 


\section{AHURI}

AHURI is a national independent research network with an expert not-for-profit research management company, AHURI Limited, at its centre.

AHURI's mission is to deliver high quality research that influences policy development and practice change to improve the housing and urban environments of all Australians.

Using high quality, independent evidence and through active, managed engagement, AHURI works to inform the policies and practices of governments and the housing and urban development industries, and stimulate debate in the broader Australian community.

AHURI undertakes evidence-based policy development on a range of priority policy topics that are of interest to our audience groups, including housing and labour markets, urban growth and renewal, planning and infrastructure development, housing supply and affordability, homelessness, economic productivity, and social cohesion and wellbeing.

\section{Acknowledgements}

This material was produced with funding from the Australian Government and state and territory governments. AHURI Limited gratefully acknowledges the financial and other support it has received from these governments, without which this work would not have been possible.

AHURI Limited also gratefully acknowledges the contributions, both financial and in-kind, of its university research partners who have helped make the completion of this material possible.

\section{Disclaimer}

The opinions in this report reflect the views of the authors and do not necessarily reflect those of AHURI Limited, its Board, its funding organisations or Inquiry panel members. No responsibility is accepted by AHURI Limited, its Board or funders for the accuracy or omission of any statement, opinion, advice or information in this publication.

\section{AHURI journal}

AHURI Final Report journal series is a refereed series presenting the results of original research to a diverse readership of policy-makers, researchers and practitioners.

\section{Peer review statement}

An objective assessment of reports published in the AHURI journal series by carefully selected experts in the field ensures that material published is of the highest quality. The AHURI journal series employs a double-blind peer review of the full report, where anonymity is strictly observed between authors and referees.

\section{Copyright}

(c) Australian Housing and Urban Research Institute Limited 2019

This work is licensed under a Creative Commons Attribution-NonCommercial 4.0 International License, see http://creativecommons.org/licenses/by-nc/4.0/. 


\section{Contents}

List of tables $\quad$ v

List of figures $\quad$ vi

Acronyms and abbreviations used in this report vii

Glossary vii

Executive summary 1

Key points 1

Key findings 1

Policy development options 3

This Study 4

1 Introduction $\quad 6$

$1.1 \quad$ Background to the research 6

$\begin{array}{lll}1.2 & \text { Indigenous housing } & 7\end{array}$

$\begin{array}{llr}1.3 & \text { Indigenous domestic and family violence } & 9\end{array}$

1.4 Policy context 11

1.4.1 Domestic violence policy and Indigenous women and children 12

1.4.2 Policy intersections: domestic violence, housing, Indigenous and child
protection policy

$\begin{array}{lll}1.5 & \text { Conceptual frameworks } & 15\end{array}$

$\begin{array}{lll}\text { 1.5.1 Housing pathways and intersectionality } & 15\end{array}$

$\begin{array}{lll}1.6 & \text { Research methods } & 16\end{array}$

2 Few pathways to safety: case study findings 19

$\begin{array}{lll}2.1 & \text { Housing and service delivery context } & 19\end{array}$

2.2 Circumstances of leaving home 20

2.3 Housing pathways 23

2.3.1 The revolving door-returning to unsafety 23

2.3.2 The difficulty of relocation 24

2.3.3 Remaining in the family home 25

2.3.4 Indigenous men's needs in the aftermath of domestic and family
violence

2.4 Policy implications 26

$3 \quad$ Improving access to safe and appropriate housing 27

3.1 Access to crisis and transitional housing 28

3.2 Access to long-term housing 30 
$4 \quad$ Improving safety 33

4.1 Crisis responses: family safety meetings 33

$\begin{array}{lll}\text { 4.1.1 Inadequate housing service responses } & 37\end{array}$

4.1.2 Normalisation of domestic and family violence and its impact on service responses

4.1.3 Unintended consequences of information-sharing for child protection notifications

4.1.4 The Safe House program 39

$\begin{array}{lll}4.2 & \text { Policy implications } & 40\end{array}$

5 Service integration: domestic and family violence, housing and child protection

5.1 Domestic and family violence, housing and risk 42

$\begin{array}{lll}5.2 & \text { Child removal and reunification } & 43\end{array}$

5.3 Collateral consequences of child removal for domestic and family violence victims

$\begin{array}{lll}5.4 & \text { Policy implications } & 45\end{array}$

$6 \quad$ Policy development options $\quad 46$

6.1 The problem: housing pathways for Indigenous women and children in the
aftermath of domestic and family violence

6.2 Analysis of current practice and responses 46

6.2.1 Lack of housing choices at every stage of the housing pathway 48

$\begin{array}{lll}6.2 .2 & \text { Service integration } & 48\end{array}$

6.2.3 Holistic service provision $\quad 50$

6.2.4 Consequences of inadequate policy 51

6.3 Supporting and empowering Indigenous women and families through culturally appropriate policy and service delivery $\quad 52$

6.4 Final thoughts 53

$\begin{array}{ll}\text { References } & 54\end{array}$ 


\section{List of tables}

Table 1: Household tenure type, persons aged 15 years and over, 2016 Census data

Table 2: Comparison of rates of reported intimate partner violence (crimes and noncrimesa): NT towns (2010-2019)

Table 3: Highest ranked recorded domestic violence related assault incidents by NSW LGA, 2018

Table 4: Service user characteristics $(\mathrm{N}=9)$

Table 5: Family Safety Framework NT: Meetings and referrals 2016-2017 


\section{List of figures}

Figure 1: Overcrowded houses by remoteness, Indigenous households: 2001, 2006 and 2011

Figure 2: Barriers to Pathways to Safety 


\section{Acronyms and abbreviations used in this report}

$\begin{array}{ll}\text { AHURI } & \text { Australian Housing and Urban Research Institute Limited } \\ \text { COAG } & \text { Council of Australian Governments } \\ \text { CRA } & \text { Commonwealth Rent Assistance } \\ \text { DV } & \text { Domestic Violence } \\ \text { DVO } & \text { Domestic Violence Order } \\ \text { NGO } & \text { Non-Government Organisations } \\ \text { NT } & \text { Northern Territory } \\ \text { NTER } & \text { Northern Territory Emergency Response } \\ \text { SHS } & \text { Specialist Homelessness Services }\end{array}$

\section{Glossary}

A list of definitions for terms commonly used by AHURI is available on the AHURI website www.ahuri.edu.au/research/glossary. 


\section{Executive summary}

\section{Key points}

- Indigenous ${ }^{1}$ women and children have very limited housing pathways to choose from in the aftermath of domestic and family violence.

- Acute shortages in crisis, transitional and long-term housing particularly in regional and remote locations mean Indigenous women and children are routinely turned away from refuges and safe houses because they are at capacity. In these circumstances they become trapped in a revolving door between crisis and transitional services, homelessness-often involving shelter with family/friends-or returning to an unsafe home. This is likely a key factor in the high rates of domestic and family violence-related injury and death amongst Indigenous women.

- Whilst Governments around Australia have improved responses to domestic and family violence through law reforms and integrated service systems they still tend to adopt a one size fits all approach that fails to respond to the intersectionality of Indigenous women's and children's experiences with domestic and family violence.

- The unintended consequences of limited housing pathways puts Indigenous women at significant risk of having their children removed by Child Protection.

Reunification is also compromised if long-term stable housing cannot be secured within generally, a 12 month timeframe given current prescribed State and Territory legislative and policy time limits for transitioning children to permanent care.

- Developing culturally appropriate responses to Indigenous domestic and family violence and improving integration between housing, domestic and family violence and child protection services should reduce rates of Indigenous women's injury and death, as well as rates of Indigenous children's out-of-home care.

\section{Key findings}

\section{Housing pathways}

This research found three dominant housing pathways available to Indigenous women and children in the aftermath of domestic and family violence. These are:

\footnotetext{
${ }^{1}$ Throughout this report the words 'Indigenous' and 'Aboriginal' are used interchangeably to refer to Australia's Aboriginal and Torres Strait Islander peoples. When reporting policy and research reports we use the terminology of the report. When referring to specific Aboriginal groups we use local, language or skin names. In using these terms we acknowledge the diversity of Australia's Aboriginal and Torres Strait Islander nations.
} 
1 Staying with family/friends

2 Staying at a refuge/safe house

3 Remaining in an unsafe home.

Women often cycle through the three options repeatedly in the search for safety in crisis situations. The acute shortages in crisis, transitional and long-term housing create significant bottlenecks within the housing pathways resulting in beds being routinely unavailable. This situation leaves women and children with little alternative but to rely on family/friends for a place to stay or to return to an unsafe home. The lack of housing choices for Indigenous women in the aftermath of domestic and family violence is, therefore a significant contributor to the high rates of Indigenous women's injury and death.

These circumstances also contribute to the high rates of Indigenous children in out-of-home care. They increase the likelihood of child protection service involvement and the risk of losing her child(ren) despite the fact she is dealing with circumstances largely outside of her control. This is a significant concern given the historical legacy of Indigenous child removal and increasing over-representation of Indigenous children in out-of-home care.

\section{Policy and service integration}

Australian governments have in the past decade focussed much needed attention on violence against women and children. They have taken steps to provide both a legislative and integrated service framework to provide support to women and children in the aftermath of violence, to hold perpetrators accountable, and to build community knowledge and awareness around these issues to prevent future violence.

These initiatives have resulted in substantial improvements to the way in which government and community services respond to domestic and family violence. Examples where these improvements can be identified include: better collaborative working relationships between government departments and service providers; provisions for the sharing of information; and through increased accountability of services 'people do what they say they are going to do'.

Women and children generally have benefited from these improvements with services becoming more attuned to identifying and meeting their needs in a timely manner. However, these initiatives are still aligned to a one size fits all model that can fail women and children who experience domestic and family violence through the lens of intersectionality.

This research found that Indigenous women and children continue to experience significant barriers to receiving a model of care that respects and embraces their difference. Indeed, their experiences give voice to being judged and questioned as to whether they are worthy victims deserving of support. This is influenced by attitudes expressing a normalisation of violence, complacency towards that normalisation, and a further undertone of racism both within the community and of most concern, within the service sector. This impacts directly on victims' safety, their housing pathways, and whether they are able to retain custody of their children.

While there have been positive advances in domestic violence policy, this research also identifies that there are still a number of areas where disconnects in policy and service integration exist. This is most profound at the intersection of housing and child protection. The heavy reliance of Indigenous populations on social housing given their general exclusion from the private housing market, particularly in regional and remote areas, means the wait for longterm accommodation can be considerable. Delays in being placed on priority housing wait lists were also regularly experienced due to a high proportion of Indigenous women having housing debt specifically related to their experience with domestic and family violence.

It was in this context that women were routinely waiting in excess of a year before being allocated long-term accommodation separate to their partner. Given housing instability is a risk 
factor for child protection service involvement, women in these circumstances are subject to ongoing surveillance. Indigenous women, in particular given the historical and intergenerational experiences with child removal, found this involvement threatening and were fearful of its consequences for their children, themselves and their families.

\section{Child protection}

The intersection between housing and child protection and its profound impact for Indigenous women and children experiencing domestic and family violence was a consistent theme throughout this research. Its significance cannot be underestimated nor the urgency to address it. With all States and Territories having now introduced legislative timeframes prescribing specific time limits (typically between 1-2 years) for children to transition from out-of-home care to permanent care, parents are needing to quickly demonstrate that they have stable housing.

Given the bottlenecks in crisis, transitional and the extended waiting times for long-term housing, it is very likely that delays in obtaining social housing will conflict with child protection law and policy. The risk that Indigenous women will lose their children permanently through no fault of their own, but rather as a consequence of systemic failures in housing policy and stock availability jeopardises not only the mother-child relationship but also puts at risk the familial and cultural continuity of Indigenous people. It is incumbent then that efforts to mitigate these unintended consequences of policy disconnect be prioritised as a matter of urgency.

\section{Policy development options}

The clearest area requiring policy development identified by this research is to address the bottlenecks in crisis, transitional and long-term housing. In part, this would involve an investment in housing stock, particularly in regional and remote areas. There is also a need for housing and child protection policy and practice managers to improve service co-ordination, to ensure the decisions of either agency do not unduly disadvantage Indigenous women from maintaining care and custody of their children. Some of the areas for policy development include:

- Managing domestic and family violence related housing debt in a way that ensures it no longer acts as a barrier to safety by delaying placement at the top of priority housing waiting lists

- Improving co-ordination between housing and Centrelink so that when women seek safety by leaving the family home, delays in establishing identity do not place her and any children at risk of homelessness

- Addressing the high rate of tenancy failure amongst Indigenous women whose pathway to safety is relocation from the family home. Given the high risk they will return to an unsafe home, It is essential they are provided with targeted tenancy and related support

- Provision of crisis accommodation for Indigenous women with (i) mental health, substance use or other behavioural problems and for (ii) women with accompanying male children aged $12-14$ years

- Employment of housing liaison officers by shelters and refugees

- Acknowledgement of the significance of housing within family safety framework strategies. Housing services should be required to ensure Indigenous women in imminent danger of serious injury or death, have appropriate options for safe, affordable accommodation, regardless of their housing history. Given the severe resource constraints on housing services this may require Commonwealth funding to provide more accommodation as well as increased resources for retro-fitting homes with increased safety measures. This is 
especially important in regional and remote locations where options for safety may be severely constrained and services are limited

- Streamlining safety upgrades of women's homes to improve speediness and reduce costs.

The severity and distinct profile of domestic and family violence on remote Indigenous communities requires new models of intervention that recognise that many women wish to remain on their community. Holistic, strengths-based, culturally responsive responses are required that, wherever possible, draw on local networks and supports. A first step is for Indigenous-led projects that have been trialled and proved effective elsewhere (Blagg, BluettBoyd and Williams 2015) to be extended to other locations.

Given the potential for extended family members (mothers, grandparents) to support women and children consideration should also be given to policies that facilitate this role. Their informal role in providing accommodation to female relatives escaping domestic and family violence could be recognised through funding for home upgrades that increase home security. The extension of programs such as the Northern Territory's 'room to breathe' could also be considered as a way of meeting the need for crisis and transitional accommodation on remote Indigenous communities.

Over the past two decades, there has been a growth in local, place based community initiatives designed to respond to Indigenous domestic and family violence. This has been made possible through government funding support. However the sustainability and continuity of these initiatives has never been assured. Given the over-representation of Indigenous women and children as victims of domestic and family violence and its ongoing impact on their lives over their life course, there is a demonstrable need for stable, recurrent funding of programs to address and support their specific needs.

These programs need to be consultative, co-designed and integrated initiatives that respond to domestic and family violence holistically. This means that they will first and foremost provide safety and support to victims, but that they will also provide support to perpetrators so that they can reflect on and change their behaviours. Housing is critical to these responses, ensuring that both parties are appropriately housed in the short, medium and long-term.

This research has also demonstrated the need for policy to have a focus on the empowerment of Indigenous women. It is critical that policy makers hear their voices, their experiences, and that they accept that Indigenous women are the 'experts of their own lives'. Their strength, resilience and resourcefulness are what keeps their families together and strong. Indigenous women demonstrate their ability to negotiate complex interpersonal, interfamilial, and outside relationships that arise from domestic and family violence every day and this is a reflection of their ability to assess risk, manage conflict and to be self-determining in complex and difficult circumstances. By identifying and supporting Indigenous women's strengths and empowering them to be self-determining we build the capacity within Indigenous communities to stop domestic and family violence and to heal those affected by it.

\section{This Study}

This research is part of a wider AHURI Inquiry into housing outcomes after domestic and family violence. This research employed a multi-method research design, comprising:

1 An evidence and policy review that identified the scholarly and policy literature to describe the profile of Indigenous domestic and family violence, the domestic violence policy prevailing at the time of research, and its intersection with housing and homelessness policy, child protection policy and criminal justice policy. 
2 Qualitative interviews with nine Indigenous women who had experienced domestic and family violence. The interviews were broad ranging covering: housing histories and current housing circumstances; experiences of support from services, family and friends; the impact of domestic and family violence on their sense of safety and their housing choices; their perceptions about the impact of their housing and support experiences on their children; and their hopes and plans for the future.

3 Qualitative interviews with 30 relevant policy and service delivery stakeholders from housing, domestic violence, legal and health related sectors. These interviews covered a range of topics including the policy and service delivery context; the effectiveness of service integration; Indigenous domestic and family violence reporting trends; service delivery limitations and opportunities; and the intersectionality of domestic and family violence with housing for Indigenous men/women and children.

The interviews were conducted in two regional cities in New South Wales and the Northern Territory. The findings were then contextualised against the evidence and policy review. 
Domestic and family violence is the largest driver of homelessness for women and children in Australia. Over the past decade Australian governments have invested in significant legislative, policy and service reforms to mitigate the impact of domestic and family violence for women and children. Little, however, is known as to the impact of these reforms on Aboriginal individuals and their families and their relationship to housing. This research therefore examines how housing and other service responses need to be improved to meet the needs of Aboriginal individuals and families in the aftermath of domestic and family violence. It draws on data from a rapid evidence and policy review; as well as qualitative interviews with nine Indigenous women service-users and 30 stakeholders including policy makers and service providers, in two regional cities in New South Wales and the Northern Territory.

\subsection{Background to the research}

The issue of domestic and family violence has become a key public policy concern in recent years, with significant reforms designed to improve the safety of women and children (COAG 2011). A key policy focus has been to improve pathways to safety with particular emphasis on more effective levels of service integration. Current policy frameworks recognise the critical role played by housing services in ensuring the safety of victims of domestic and family violence to some extent, although this varies by jurisdiction and location. This is most evident in efforts to increase access to crisis and transitional accommodation, and to support housing stability and safety through programs such as Safe at Home which enable some women to remain in their own home through removal of the perpetrator (Spinney 2012).

Despite these efforts, domestic and family violence continues to be the largest driver of homelessness for women and children with AlHW data showing that the proportion of clients requiring Specialist Homelessness Services (SHS) due to domestic and family violence is increasing rather than declining (AlHW 2018b; Spinney 2012). In 2017-18, 42 per cent of SHS clients identified as experiencing domestic and family violence, compared with 40 per cent in the previous reporting year (AlHW 2018b).

This project is one of three empirical projects designed to inform the Evidence-based Policy Inquiry, Integrated Support for Vulnerable Families, that asks:

Where, and in what circumstances is housing support for vulnerable families integrated with other forms of support, to enhance safety and wellbeing?

In considering this question, this project focuses specifically on the needs of Indigenous women and children who are severely over-represented in rates of both homelessness and domestic and family violence. In 2017-18, Indigenous people made up 3.2 per cent of the Australian population, yet comprised 25 per cent of SHS clients. Within this group, domestic and family violence was the second most common reason for homelessness (25\%) (AlHW 2018b). Twenty-two per cent of these Indigenous clients were children aged under 10 years, compared with 15 per cent of non-Indigenous clients. Evidence of the efficacy of current programs aimed at providing housing assistance to Indigenous victims of domestic and family violence via integrated support, is both lacking and challenging to obtain.

The research question guiding this project is: 
How can housing and other service responses to family and domestic violence be improved to meet the needs of Aboriginal individuals and families?

To address this question, the project asks the following three subsidiary questions:

4 What housing choices are available for Indigenous individuals and families in the aftermath of violence? How do these differ depending on location, i.e. urban, regional and remote?

5 What types of support do Indigenous women find helpful when moving house after violence; and what assists them to plan for the immediate, medium and long-term future? How is this affected by location?

6 How are achieving effective outcomes affected by other state and Australian Government policies and practices, e.g. welfare restrictions and child protection regulations?

The research employed a multi-method research design, comprising:

- rapid evidence and policy review

- interviews with Indigenous women who have experienced domestic and family violence

- interviews with policy and service delivery stakeholders.

Data collection took place in two sites in regional towns in New South Wales and the Northern Territory.

\subsection{Indigenous housing}

Indigenous Australians are located at the bottom of the nation's distribution of economic goods with significant implications for their health and wellbeing (Productivity Commission 2016; SCRGSP 2016). Housing exclusion is one of the factors contributing to this, with a mix of historical, structural and cultural factors generating difficulties accessing and sustaining stable, safe and affordable housing. As well as poverty and disadvantage, these factors include distinctive family and community relationships that are often in conflict with mainstream housing systems (Habibis, Birdsall-Jones et al. 2011; Habibis, Memmott 2013; Milligan, Phillips et al. 2011; Moran, Memmott et al. 2016).

Table 1: Household tenure type, persons aged 15 years and over, 2016 Census data

\begin{tabular}{|c|c|c|c|c|c|c|}
\hline \multirow[t]{2}{*}{ Tenure type } & \multicolumn{5}{|c|}{ Indigenous } & \multirow{2}{*}{$\begin{array}{r}\text { Non-Indigenous } \\
\text { Total }\end{array}$} \\
\hline & $\begin{array}{l}\text { Major } \\
\text { cities }\end{array}$ & $\begin{array}{r}\text { Inner } \\
\text { regional }\end{array}$ & $\begin{array}{r}\text { Outer } \\
\text { regional }\end{array}$ & Remote & Total & \\
\hline Owners (\%) & 40.4 & 42.2 & 39.2 & 27.7 & 38.1 & 66.3 \\
\hline \multicolumn{7}{|l|}{ Renters } \\
\hline Social housing & 17.3 & 15.5 & 19.0 & 37.4 & 21.5 & 3.7 \\
\hline Private renters & 36.2 & 35.4 & 32.5 & 18.3 & 32.4 & 24.6 \\
\hline Other renters & 1.9 & 2.6 & 4.3 & 10.5 & 3.4 & 1.8 \\
\hline Total renters (\%) & 55.4 & 53.5 & 55.8 & 66.3 & 57.3 & 30.0 \\
\hline Other tenure & 0.7 & 0.6 & 0.7 & 1.1 & 0.7 & 1.0 \\
\hline Not stated & 3.5 & 3.7 & 4.4 & 4.9 & 3.9 & 2.7 \\
\hline
\end{tabular}

Source: Adapted from Australian Institute of Health and Welfare 2019, Aboriginal and Torres Strait Islander people: a focus report on housing and homelessness. Cat. no. HOU 301, AlHW, Canberra,

https://www.aihw.gov.au/getmedia/1654e011-dccb-49d4-bf5b-09c4607eecc8/aihw-hou-301.pdf.aspx?inline=true 
The high cost of home ownership means that less than 40 per cent of Indigenous adults are home owners, compared with 66 per cent of the non-Indigenous population (AlHW 2019a) (see Table 1 above). Most live in rental accommodation, with a high proportion (21.5\%) in social housing due to difficulties accessing private rentals because of high rental costs and discrimination (Stracey 2003; Roberts, Fuller et al. 2006). The reliance on social housing increases with remoteness, with 37.4 per cent of households in remote communities living in social housing, compared with 17.3 per cent in major cities. By comparison, the total proportion of the non-Indigenous population living in social housing is 3.7 per cent. Social housing policy therefore plays a critical role in the wellbeing of Indigenous individuals and families.

Housing stability is an issue for many Indigenous households, as large, crowded, multi-family households, together with frequent visits from kin, heighten the risk of tenancy breaches and eviction. Indigenous cultural norms of mutual reciprocity create relationships of obligation and systems of exchange between family members that make it difficult to manage other family members and visitors (Moran, Memmot et al. 2016). The tenancy requirements of mainstream rental housing are based on stable household arrangements, based around a nuclear family, rather than the more fluid occupancies and multi-family arrangements that characterise many Indigenous households (Habibis, Memmot et al. 2013).

Figure 1: Overcrowded houses by remoteness, Indigenous households: 2001, 2006 and 2011

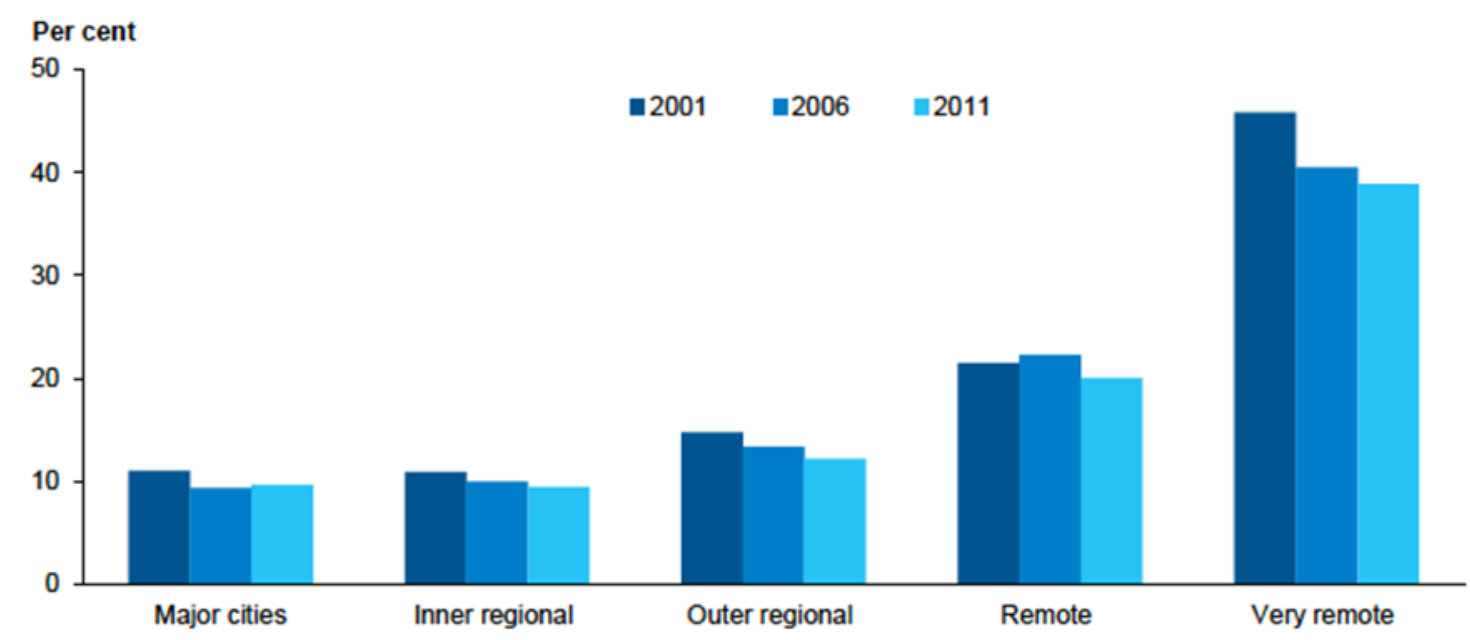

\footnotetext{
Notes

1. An overcrowded household is one in which the dwelling required 1 or more extra bedrooms to accommodate usual residents, based on the Canadian National Occupancy Standard.

2. Percentages are based on the number of dwellings for which the level of crowding could be determined.

3. Data for this figure are shown in Appendix Table B3.2.

Source: AlHW 2014, Housing circumstances of Indigenous Australians: tenure and overcrowding, p.21.
}

Housing shortages, substandard housing and differences in the way that Indigenous people use household space, result in high levels of crowding and homelessness. Crowding occurs at rates almost five times that of non-Indigenous households, with rates rising to 50 per cent of houses in very remote locations (Productivity Commission 2016; SCRGSP 2016) (see Figure 1 above). Levels of homelessness are four times that of the non-Indigenous population, with children presenting to homelessness services at rates eight times that of the non-Indigenous population (Productivity Commission 2014; SCRGSP 2014). As well as having a detrimental impact on health, mental health, education and employment (Fien and Charlesworth 2012), crowded households have been implicated in both domestic and family violence and child abuse (Wild and Anderson 2007). 


\subsection{Indigenous domestic and family violence}

The experience of domestic and family violence in Indigenous communities across Australia, but particularly in regional and remote areas, regularly captures the attention of our nation's media, and has done so since the early 1990s. The nation is familiar with the bruised and battered images of Indigenous women and children, and accepts that the occurrence of violence in Indigenous communities and among individuals is disproportionately high in comparison to the Australian population as a whole (AlHW 2016). In the Northern Territory, which has the highest proportion of Indigenous adults of any Australian jurisdiction, the rate of domestic and family violence was more than double that of any other jurisdiction at 1,730 victims per 100,000 persons (Northern Territory 2018: 13). Within the Northern Territory, rates of intimate partner violence vary significantly, with remoteness a contributing factor. An analysis of Northern Territory Police data on intimate partner violence reported to the police between 2009 and 2014 found that incidents ranged from 125 per 1,000 population in Casuarina just outside Darwin, compared with 1,269 per 1,000 population in Tennant Creek (Kerr 2017: 75). Drugs and alcohol are a major contributing factor, with data from Katherine Hospital estimating that 90 per cent of their cases with Indigenous patients were alcohol related and involved family and domestic violence (Casey, Entwistle et al. 2012: 34).

Table 2: Comparison of rates of reported intimate partner violence (crimes and noncrimesa): NT towns (2010-2019)

\begin{tabular}{|c|c|c|c|c|c|}
\hline \multicolumn{6}{|c|}{ Total Incidents } \\
\hline & Total & $\%$ of Total & Population & $\begin{array}{r}\% \text { of NT } \\
\text { population }\end{array}$ & $\begin{array}{r}\text { Incidents } / 1,000 \\
\text { population }\end{array}$ \\
\hline Alice Springs & 14,056 & 22.7 & 31,250 & 12.8 & 450 \\
\hline Casuarina & 7,280 & 11.8 & 58,470 & 23.9 & 125 \\
\hline Darwin (City) & 6,161 & 10 & 26,281 & 10.7 & 234 \\
\hline Katherine & 7,023 & 11.4 & 11,187 & 4.6 & 628 \\
\hline Palmerston & 6,655 & 10.8 & 33,949 & 13.9 & 196 \\
\hline $\begin{array}{l}\text { Remote } \\
\text { North }\end{array}$ & 10,298 & 16.7 & 45,000 & 18.4 & 229 \\
\hline $\begin{array}{l}\text { Remote } \\
\text { South }\end{array}$ & 4,093 & 6.6 & 13,622 & 5.6 & 301 \\
\hline Rural & 1,617 & 2.6 & 21,686 & 8.9 & 75 \\
\hline $\begin{array}{l}\text { Tennant } \\
\text { Creek }\end{array}$ & 4,613 & 7.5 & 3,634 & 1.5 & 1,269 \\
\hline NT Total & 61,796 & 100 & 245,079 & 100 & 252 \\
\hline
\end{tabular}

Non-crimes are reports of intimate partner violence involving both men and women involving low-level conflict, and with no perpetrator or victim identified.

Source: J. Kerr, 'A descriptive analysis of the characteristics, seriousness and frequency of Aboriginal intimate partner violence in the Northern Territory, Australia: a strategy for targeting high harm cases', M App Crim, Cambridge University, 2017.

One of the explanations for the high levels of violence in Alice Springs, Katherine and Tenant Creek is that they receive large numbers of visitors because these locations are meeting points across a vast surrounding region. This is linked to violence partly because of the pressures 
created by crowding, public space dwelling and access to alcohol. These rates are significantly higher to those reported in other publications and in other Australian jurisdictions. They demonstrate based on incidents reported to Police just how pervasive the problem of domestic and family violence is in the Northern Territory.

NSW police data reveals a similar profile of high rates of domestic and family violence in towns such as Walgett, Broken Hill and Dubbo (see Table 3 below), where there is a high proportion of Indigenous residents. Given the reluctance of many victims to report incidents of domestic and family violence, it is likely that these figures are an underestimate of the size of the problem (Cripps and McGlade 2008).

Table 3: Highest ranked recorded domestic violence related assault incidents by NSW LGA, 2018

\begin{tabular}{lrr} 
Incident Local Government Area & Rate per $\mathbf{1 0 0 , 0 0 0}$ & Rank \\
\hline Walgett & $2,374.8$ & 1 \\
\hline Coonamble & $1,637.3$ & 2 \\
\hline Moree Plains & $1,353.1$ & 3 \\
\hline Narromine & $1,261.8$ & 4 \\
\hline Broken Hill & $1,147.0$ & 5 \\
\hline Dubbo Regional & $1,092.3$ & 6 \\
\hline Wentworth & $1,032.7$ & 7 \\
\hline Cobar & 972.7 & 8 \\
\hline Lachlan & 931.7 & 9 \\
\hline Gilgandra & 871.2 & 10 \\
\hline NSW Total & $\mathbf{3 7 6 . 2}$ & $\mathbf{n . c .}$ \\
\hline
\end{tabular}

Source: BOSCAR 2018 Domestic violence statistics for NSW,

https://www.bocsar.nsw.gov.au/Pages/bocsar pages/Domestic-Violence.aspx.

These rates of domestic and family violence are a substantial contributor to the overrepresentation of Indigenous women in homicide rates. From 2012-13 to 2013-14, two in five Indigenous homicide victims (41\%) were killed by a current or previous partner, twice the rate of non-Indigenous victims (Bryant and Bricknell 2017). In 2014-15 Indigenous women were 32 times as likely to be hospitalised due to domestic and family violence as non-Indigenous women demonstrating the seriousness of injuries inflicted as a consequences of domestic and family violence (Productivity Commission 2016; SCRGSP 2016).

Those most vulnerable to domestic and family violence are younger Indigenous women, typically aged $25-44$, however, those aged $15-24$ are also likely to experience violence at rates higher than those younger or older (45+ years) (ABS 2019). The type of domestic and family violence experienced most often by Indigenous women is physical violence, with the severity of the injuries often requiring medical intervention (ABS 2019; AlHW 2018a; SCRGSP 2016).

While it has widely been established that domestic and family violence within Indigenous communities needs to be understood as both a cause and effect of social disadvantage and intergenerational trauma, it must also be recognised that it takes place in a context where the practice of power and control by one partner against another is evident (AIHW 2018a; ABS 
2019; Cripps and Adams 2014). The types of violence that take place in the context of power and control include: physical violence; sexual violence; threats; emotional abuse; financial abuse; jealousy; isolation; lateral violence; and payback. The latter two are particularly prevalent when police become involved and extended family and friends exert pressure on victims to not 'make trouble' for the family (Cripps and Adams 2014).

The characteristics of domestic and family violence in the context of power and control are in contrast to the situational violence that has also been described as taking place in Indigenous households (Johnson 2008; Nancarrow 2016). In situational violence, the violence typically does not form a pattern, it occurs when one or both partners handle conflict with violence. It differs from domestic and family violence because the violence is often specific to the situation and generally minor, it does not escalate over time. The violence consistently described by Indigenous women in the literature, in cases before the courts, and also in the stories shared as part of this research, were consistent with relationships characterised by power and control. In these relationships, where alcohol or drug abuse was also present, the situations confronted by the women were precarious and unpredictable. The disinhibiting effect of the alcohol and/or drugs served to increase the risk and seriousness of the violence.

This experience of violence is also impacted by the influence of cultural and kinship responsibilities and obligations that define and shape the dynamics of relationships between individuals, families and community members more broadly. This can have both positive and negative ramifications as in, for example, the importance of extended family in child rearing, its implications in the provision of care and support and the significance of the sharing of cultural knowledge in providing individuals, families and communities with a strong sense of identity, strength in common experiences, connectedness and social cohesion.

Cultural and kinship obligations are also implicated in continual family visitors, who may stay for periods varying from a few hours, to days, weeks or months, creating stress within the household. Impacts can include the potential for overcrowding, trouble with housing authorities for unauthorised visitors, financial implications for food, electricity, gas, water, and also managing behaviour if visitors are drinking. It should be noted that in these contexts, women and children may not be in positions within the family unit that would facilitate challenging or indeed affecting positive behavioural change of other family members, without support.

\subsection{Policy context}

Over the last decade governments across all jurisdictions have responded in a myriad of ways to increasing public awareness of the extent of, and harms caused by, domestic and family violence. These responses are given impetus, focus and direction by the Australian Government's National Plan to Reduce Violence against Women and Children 2010-2022 which was endorsed by the Council of Australian Governments (COAG). The plan provides all states and territories with an identifiable domestic and family violence strategy, and all are engaged in reviewing, amending and improving domestic and family violence-related legislation to support it.

Current domestic violence policy responses are framed around an 'integrated' support model that aims to increase information sharing, improve coordination of crisis responses, build the capacity of frontline workers across relevant sectors, and strengthen partnerships between government agencies and non-Government Agencies (NGOs), including housing services. As Spinney (2012: 2) argues, 'the most effective homelessness prevention measures for women and children who have experienced domestic and family violence often combine legal/judicial, housing and welfare policy and practices in an integrated manner in order to improve their safety'. 
However, current initiatives overwhelmingly target generic populations, despite the considerable socio-economic and cultural variability within the victim population and their different life experiences and situations (AlHW 2014). There is also little understanding of the extent to which programs designed with an urban focus are easily transferable to rural and remote contexts. This is particularly problematic for Indigenous populations where policy assumptions may be poorly calibrated against Indigenous cultural and socio-economic realities (Spinney, Habibis et al. 2016).

Moreover, where implemented, integration attempts between service areas may not be robust enough to support long-term positive outcomes as they are often not constructed to deal with complex matters (valentine and Breckenridge 2016; Spinney 2012). Notwithstanding government strategic responses exhorting a 'whole-of-government' approach, services continue to appear 'fragmentary and localised' (Flanagan, Blunden et al. 2019: 14). The meaning of what comprises 'integration' is also open to interpretation. For example, Flanagan, Blunden and colleagues (2019: 26) argue that for government policy settings, and at a day-to-day practice level, 'integration is less about specific initiatives or programs and more about the maintenance of productive, mutually-supportive working relationships between agencies and/or workers'. Critically, however, no amount of integration will help if there are not funded services and programs to connect with-an issue particularly relevant to Indigenous populations in regional and remote locations where services are constrained by short-term government funding. This ultimately impacts the long-term effectiveness of initiatives responding to domestic and family violence (Cripps and Davis 2012; Cripps 2007).

\subsubsection{Domestic violence policy and Indigenous women and children}

Indigenous policy, historically, has tended to shift between principles of guardianship, selfdetermination and equality. These compete for dominance, and although one principle may be dominant for decades, it always exists in tension with the other two (Sanders 2009). Although the dominance of particular policy principles map broadly onto the major Indigenous public policy eras of protection, assimilation and self-determination, at any one time, all three principles are in play. In recent years a swing towards guardianship, most notably evident in the Northern Territory Emergency Reponse has given way to renewed emphasis on selfdetermination, alongside a continuing concern with equality. This can be seen in the National Plan which specifically targets Indigenous women and children, through expectations that they should be considered in relation to all aspects of the plan, and through national outcomes of strengthening Indigenous communities. This focus needs to be placed in the context of Australia's status as a signatory to the United Nations Declaration on the Rights of Indigenous Peoples (2007) with policy implications including principles of self-determination, recognition of the distinctive nature of Indigenous culture, the need for culturally appropriate service provision, improving service access and ensuring Indigenous children maintain their sense of cultural identity and community connectedness (Closing the Gap Clearinghouse 2016).

One strategy to improve service integration and timely response that is operating in many jurisdictions is the establishment of regular meetings between key services to coordinate responses for individuals identified as in imminent danger of serious harm. In the Northern Territory, the Family Safety Framework is one of the programs operating under the Territory's Safe, Respected and Free from Violence 2018-2028 strategy. This serves as an informationsharing forum and provides a range of primary to tertiary interventions, including measures to improve the safety of the home as well as priority access to crisis accommodation, and to longterm, secure housing. The lead agency is the NT Police with seven other agencies/organisations participating, including the Northern Territory Department of Housing and Community Development, which includes both housing and child protection services.

In New South Wales, the state's Safer Pathway program is a similar initiative that operates under its Domestic and family violence Blueprint for Reform 2016-2021 strategy. Both 
strategies include a domestic violence (DV) safety assessment tool designed to assess the level of domestic and family violence threat to victims, with services either mandated or strongly encouraged to use the tool when they attend a domestic and family violence incident. At this stage the effectiveness of such tools in accurately identifying risk is unclear (Ringland 2018).

Other features of the NSW strategy include a central referral point to electronically manage and monitor referrals and a state-wide network of local coordination points that facilitate local responses and provide victims with threat assessment, safety planning, case coordination and referrals to a range of service providers for ongoing support. In both jurisdictions the strategy is limited to a discrete number of locations.

Most jurisdictions also have 'safe at home' policies (funded by both the Australian and State/Territory Governments) which are designed to allow women to remain in their homes, either by forcibly removing perpetrators from the family home, or by supporting the woman to move to a home of her choice. Assistance varies but may include rental assistance, and for high risk cases, housing upgrades to provide additional security. The extent to which these policies have been implemented is variable and their operation was limited in the two case study sites that were the subject of this research.

\subsubsection{Policy intersections: domestic violence, housing, Indigenous and child protection policy}

The principal link between domestic violence and housing policy is through the National Partnership Agreement on Homelessness which prioritises women and children escaping family violence. Funding priority is given to frontline services focusing on women and children escaping domestic and family violence and homeless youth or youth at risk of homelessness. Housing assistance strategies are also directed towards strengthening accommodation options for women and children escaping violence, alongside other strategies to improve crisis services. This has resulted in stronger ties between domestic violence and homelessness services, such as NSW's Going home, staying home reforms.

Nationally, the principal policy framework for Indigenous affairs is the National Indigenous Reform Agreement, which sets out a commitment by the Australian, States and the Northern Territory Governments, to a National Integrated Strategy for Closing the Gap in Indigenous Disadvantage (COAG 2008). Efforts to improve community safety are the main link to the National Plan to Reduce Violence Against Women and their Children. This has mostly taken the form of criminal justice and child protection responses rather than measures addressing the needs of women and children in situations of domestic and family violence to stay together safely. ${ }^{2}$ Within the states and territories there are a number of initiatives that specifically target Indigenous domestic and family violence. However, most of these programs focus on community education and capacity building to address violence or alternatively improved justice responses rather than housing support (AlHW 2016). One exception is the Indigenous Family Safety Program which established safety houses in 18 remote Northern Territory communities for Indigenous women escaping domestic and family violence (see Chapter 4.1.4). Many of these initiatives are funded on short-term contracts and are rarely evaluated, so there is a limited evidence base on what is or is not working to reduce domestic and family violence in the Indigenous context (Cripps and Davis 2012; HREOC 2008).

Overall, policy frameworks pay limited attention to the distinct profile of Indigenous housing as it impacts on domestic and family violence, in terms of the extent of exclusion from mainstream

\footnotetext{
2 Under the Closing the Gap Refresh there are a number of new targets that include a significant and sustained reduction in violence against Indigenous women and children, as well as progress to eliminate the overrepresentation of Aboriginal children in out-of-home care.
} 
housing markets, problems in accessing housing and homeless services, and the vulnerability of victims to tenancy breaches and housing insecurity as a result of the physical and financial abuse of male family members (Culhane, Webb et al. 2003; Courtney, McMurtry et al. 2004). There are few programs that specifically address the high risk of homelessness that arise from this (Blagg, Bluett-Boyd et al. 2015), and scant acknowledgement of the psychological and emotional barriers that Indigenous women face in establishing a home away from family and community (Habibis, Birdsall-Jones et al. 2011; NAAJA 2016).

The long-term decline of government investment in social housing (Flanagan, Blunden et al. 2019 ) is especially problematic for Indigenous populations given the high proportion of Indigenous people who rely on social housing (see Chapter 1.2). Although there has been some attempt to improve access to private rental through Commonwealth Rental Assistance (CRA) programs, this is ineffective for low-income individuals and families because CRA is funded at a flat rate, and as such the cost may still be unsustainable for many individuals and families (Flanagan, Blunden et al. 2019: 59). This is especially the case when low income is compounded by Indigeneity and female-headed households. The same is true for other rental subsidy programs such as the NSW Government's program Rent Choice Start Safely (see Chapter 3). Moreover, in many places with high proportions of Indigenous populations there is a severe shortage of rental properties, making such strategies irrelevant.

Policy tensions between domestic violence and child protection also impact especially harshly on Indigenous women and children. Despite concern at the number of Indigenous children in out-of-home care (AlHW 2019a), current child protection policy and related legislation often holds women accountable for the safety of children. The National Plan's recognition of the harmful effects of domestic and family violence on children has resulted in some jurisdictions defining exposure to domestic and family violence as a form of child abuse and this has been enacted in their child protection legislation. Consequently, child protection officers may remove children if parents are unable to provide a safe environment for children as a result of violence within the home (Funston, Herring and ACMAG 2016: 54).

This is especially a concern where legislation requires mandatory reporting of child abuse with some jurisdictions requiring housing officers to report any concerns (AlHW 2016). Despite the policy emphasis on culturally appropriate service provision, rates of removal of Indigenous children continue to rise with some concern that this is related to safety issues due to domestic and family violence (AlHW 2018a; AlHW 2019b; Courtney, McMurtry et al. 2004; Victorian Commission for Children and Young People 2016). In 2017-18 Indigenous children were the subject of substantiated abuse and/or neglect reports at almost seven times the rate of nonIndigenous children, and they were admitted to out-of-home care at nine times the rate of nonIndigenous children (AlHW 2019b). These figures are important as it has been estimated that in some jurisdictions exposure of Indigenous children to domestic and family violence is as high as 88 per cent (Victorian Commission for Children and Young People 2016). However, there is no public data available that conclusively determines the number of children who have been removed as a direct consequence of domestic and family violence.

In complex domestic and family violence situations, child protection services often blame the mother for failing to protect the children and place significant conditions on the care and custody of their children (Cripps 2012). This doubly punishes Indigenous women who are not only victims of violence but who also risk removal of their children despite severely limited options to ensure their own safety or that of their children (Cripps 2012; Cripps and Adams 2014; Culhane, Webb et al. 2003; Courtney, McMurtry et al. 2004; Hinton 2018). 


\subsection{Conceptual frameworks}

In answering the research questions, this project takes a comprehensive view of how housing policy affects Indigenous individuals and families. This recognises the significance of extended kinship networks within Indigenous populations, which entail responsibilities for both genders, that can inhibit women's choices in securing safety for themselves and their children (Cripps and Adams 2014). A holistic approach also acknowledges the context of colonisation and its impact on lateral violence in which poverty and feelings of disempowerment, loss and intergenerational trauma may result in a high level of physical and other forms of abuse between family and community members (HREOC 2011).

The conceptual framework also follows the Inquiry's concern with housing pathways and intersectionality. The former acknowledges that the housing trajectories of individuals and households do not always progress along a linear trajectory of improving housing circumstances but are instead shaped by a combination of housing preferences, individual context and circumstance, changing household needs and lifecourse stages (Clapham, Mackie et al. 2014, Wiesel, Easthope et al. 2012: 15). The housing pathways approach is especially useful for analysing the trajectories of Indigenous individuals and households where kinship networks, financial constraints and limited housing options play a critical role in determining housing choices. Intersectionality draws attention to the structural factors that shape the complexities of individual experience, especially gender and ethnicity, as a tool to better inform policy making.

\subsubsection{Housing pathways and intersectionality}

A housing pathways approach is increasingly utilised in the social housing literature to inform deeper understandings of housing and homelessness. Clapham $(2002: 63,68)$ defines it as a focus on 'patterns of interaction (practices) concerning house and home, over time and space' and 'social practices of a household relating to housing over time and space'. For Clapham:

The housing pathway of a household is the continually changing set of relationships and interactions that it experiences over time in its consumption of housing. These may take place in a number of locales such as the house, the neighbourhood or the office of a landlord or estate agent (Clapham 2005: 27).

Importantly, the housing pathways approach is not a theory or indeed a research methodology, though it can form a framework for one (Clapham 2002: 63-64). As Clapham (2005: 27-28) argues, the housing pathways approach is better regarded as 'a framework of analysis-a way of framing thought', stating:

The concept of a pathway is offered as a way of ordering the housing field in a way which foregrounds the meanings held by households and the interactions which shape housing practices as well as emphasising the dynamic nature of housing experience and its inter-relatedness with other aspects of household life (Clapham 2002: 64).

Because it is 'dynamic' in its recognition of individual contextual change, as opposed to being a rigid framework, the 'housing pathways approach' is adaptable to circumstances in a way that previous theoretical approaches are not. This allows for a more nuanced understanding of the efficacy of interventions.

For the current Inquiry, this approach enables a focus on individual actors and their experience of 'past decisions and a changing context' and can scale up to consider a wider household and community while still recognising differences (Clapham, Mackie et al. 2014). In this way we can ascertain what the actual needs of individuals, households and communities are to better direct policy, programs and services. A housing pathways approach encourages identification of integration avenues and is useful for mapping where gaps may exist. 
Critically, it has been identified that there is a difference between how housing pathways and experiences are construed in much of the academic literature-as a non-linear journeycompared with the emphasis in some government policy approaches which conceive of 'housing pathways' as a 'trajectory', in which assistance provided is only temporary while the individual moves upwards to independence (Flanagan, Blunden et al. 2019: 18-19). As noted by Flanagan, Blunden et al. (2019: 19), for the government constructions of 'housing pathways' as a linear progression to work, considerably more 'independent' housing stock needs to be available. Looking at domestic and family violence in particular, a pathways approach allows us to ask and examine questions such as: How do services respond? Do they respond in a linear or a non-linear way? Is everyone treated the same? Pathways ask us to look at the individual experience and eschew a one-size-fits-all response.

Intersectionality has been described as

$[T]$ he ways in which the experiences of women are formed by the intersections of gender with other aspects of identity, such as Indigeneity, class, disability and age. Intersectionality theory emerged as a critique of the neglect of race in analyses of violence against women...' (Flanagan, Blunden et al. 2019: 12).

Intersectionality can be understood as particular characteristics, contexts and experiences that a person brings with them to a given situation, and the complex ways in which these intersect with each other to inform an individual's perspective. An awareness of intersectionality can lead to a better understanding of contexts, responses to, and appropriateness of, service options offered. Of importance for policy makers and frontline agencies, intersectionality reminds us that a person brings their dispositions and experiences with them-when seeking assistance for example - and that may influence how they interact with a service provider.

Intersectionality is an approach of general application whereas housing pathways focuses specifically on decision-making contexts within housing. Taken together, these two concepts speak and relate to each other to present a more holistic view of appropriate action. For example, intersectionality may assist understanding of why a particular decision regarding housing was made, while a housing pathways approach identifies and tracks decisions made.

\subsection{Research methods}

The research employed a multi-method research design, comprising:

- An evidence and policy review focusing especially on the two case study jurisdictions of New South Wales and the Northern Territory. This desktop review identified the scholarly and policy literature to describe the profile of Indigenous domestic and family violence, the domestic violence policy prevailing at the time of research, and its intersection with housing and homelessness policy, child protection policy and criminal justice policy.

- Qualitative interviews with Indigenous women who have experienced domestic and family violence. The research design proposed recruitment of 24 Indigenous individuals who have experienced domestic and family violence in the previous two years. However, the sensitive nature of the topic made recruitment difficult with nine rather than the intended 24 respondents interviewed. Interviews covered housing histories and current housing circumstances; experiences of support from services, family and friends; the impact of domestic and family violence on their wellbeing, sense of safety and risk of their housing choices in response to domestic and family violence; their hopes and plans for the future; and their perceptions about the impact of their housing and support experiences on their children. 
The interviews excluded questions about the violence experienced by the women as the focus was on their engagement with the services and support system particularly housing services and experiences. Table 4 below provides some further characteristics of these respondents.

Table 4: Service user characteristics $(\mathrm{N}=9)$

\begin{tabular}{llll} 
Accommodation & Duration & Income & With children \\
$\begin{array}{l}\text { Dept of Housing, } \\
\text { Long grass }\end{array}$ & $\begin{array}{l}2 \text { months } \\
7 \text { years }\end{array}$ & Centrelink & No \\
\hline $\begin{array}{l}\text { Homeless } \\
\text { Couch surfing }\end{array}$ & 12 months & $\begin{array}{l}\text { Casual } \\
\text { employment }\end{array}$ & No: out-of-home care \\
\hline Dept of Housing & 2 years & Centrelink & Yes \\
\hline $\begin{array}{l}\text { Dept of Housing sharing } \\
\text { with other family }\end{array}$ & Not available & Centrelink & No \\
\hline Dept of Housing & Not available & Centrelink & Yes \\
\hline Aboriginal Housing & Not available & Centrelink & Out-of-home care \\
\hline Dept of Housing & 2 years & Employed & Out-of-home care \\
\hline Aboriginal Housing & Not available & Centrelink & Yes \\
\hline Homeless & 18 months & Centrelink & Yes
\end{tabular}

Source: Authors.

- Qualitative interviews with relevant policy and service delivery stakeholders. Sectors covered included housing, domestic violence, legal and health services. While the proposal planned for 10-15 interview respondents in each research site, additional interviews were undertaken to compensate for the shortfall in service user interviews. A comprehensive sample of relevant government and non-government services were recruited, with 30 interviews across the two sites. Interviews covered a range of topics including the policy and service delivery context; the effectiveness of service integration; reporting trends relating to Indigenous domestic and family violence; service delivery limitations and opportunities; and the intersectionality of domestic and family violence with housing for Indigenous men/women and children.

- The interviews were conducted in two regional cities in New South Wales and the Northern Territory. Both were characterised by distance from larger population centres, high proportions of Indigenous residents, tight housing markets resulting in high levels of crowding and homelessness, and limited access to domestic violence and related services. Traditional practices, including population mobility, were stronger in the Northern Territory, with many Aboriginal people speaking English as a second or third language, but in both locations strong kinship networks, together with a moral economy of sharing were prevalent. The findings were broadly similar and have relevance for other jurisdictions because of the similar policy approaches and the context of Indigenous cultural difference and housing exclusion.

- Interviews were transcribed and analysed thematically by case study site, using the research questions and interview schedule as the analytical framework. Quotes from the interviews are presented as illustrative excerpts only, with any potentially identifying 
information removed to protect the anonymity and confidentiality of research participants. The interview findings are reported in Chapters 2, 3, 4 and 5. 


\section{Few pathways to safety: case study findings}

Through the lens of housing pathways and intersectionality, the housing choices and experiences of Indigenous women and children in the aftermath of domestic and family violence were examined. This lens provided the opportunity to ask and examine questions such as: How do services respond? Do they respond in a linear or non-linear way? Is everyone treated the same? Pathways ask us to look at the individual experience and to examine the 'fit' of current responses, identifying gaps and opportunities for further reform.

The circumstances of leaving home in the aftermath of domestic and family violence for Indigenous women and children are complex. Women are attempting to balance the needs of multiple stakeholders to secure safety for themselves and their children. Their housing pathways are often limited to three options:

- staying with family/friends

- staying at a refuge/safe house

- staying at home.

The acute shortages in crisis, transitional and long-term housing create significant bottlenecks within the housing pathways resulting in beds being routinely unavailable. This situation leaves women and children with little alternative but to rely on family/friends for a place to stay or to return to an unsafe home.

Recent law reforms to Domestic Violence Orders that can exclude men from the family home have been considered an alternative to the women leaving, particularly with the added support of housing safety upgrades. However, the research found the men rarely had housing options, and even if they were excluded, because they were effectively homeless, they usually returned to the family home, making this policy largely ineffective in the Indigenous context. This points to the need for a holistic response to domestic and family violence that caters to the housing and support needs of both men and women.

\subsection{Housing and service delivery context}

The lack of affordable housing in the towns and cities where many Indigenous people live is one of the contributors to high levels of crowding, and this was true of both case study locations. The private rental market was small, and neither town had escaped the national trend of increasing rates of housing stress. In one location the median rent for a three-bedroom home had doubled between 2016 and 2018 (ABS 2016). Unemployment rates for Aboriginal and Torres Strait Islander populations are much higher than for non-Indigenous people, with almost 50 per cent of the population being unemployed in many regional towns (PMC 2017). Even when they are employed, average earnings are substantially less than among non-Indigenous people (ABS 2016). At a time when rates of both income support and the wages of low-income earners have remained relatively static (ABS 2016), the private rental market is out of reach for 
many Indigenous people. Accessing the private rental market is especially difficult during the tourist season when rents increase due to rising demand for temporary accommodation.

Discrimination is a further barrier to the private rental market, with many informants describing landlords and real estate agents as reluctant to rent properties to Indigenous people. Small towns are often familiar with local families and respondents reported that local knowledge of prior rental history including damage or not paying rent, or a history of using alcohol, drugs or violence will mean families are precluded from entering the private rental market.

Consequently, the accommodation options for most respondents was limited to crisis and transitional accommodation or couch surfing with friends or relatives. For long-term housing, small private rental markets, together with high rents and discrimination meant community, public or Aboriginal housing was the only option.

As regional centres, both locations had a range of services relevant to women and children escaping domestic and family violence. These included a women's refuge, Aboriginal legal services, social services offered through organisations such as Mission Australia and Anglicare for example, a police station, and health services, including a hospital. More specific specialist services were also available on a periodic basis when professionals would fly in/fly out from larger urban environments.

\subsection{Circumstances of leaving home}

The decision to stay or leave the family home is complex due to a combination of practical and cultural barriers. These are captured in Table 5 below which highlights the often competing messages and demands of both family and community, and service providers, as the woman considers how she will manage these competing pressures and establish a safe place to stay. A critical factor is the strength of ties to family and community which make it difficult to leave, despite the risks to personal safety:

For many women, exiting your community or area of community and family is not a
real option, and it's very difficult as well. Hence why I think that often women are
seeking strategies where they can maintain the relationship and the links, but they
want the violence to stop, or they even want some at least short-term separation. It
becomes really quite difficult and challenging for those women where the actual
marriage also involves really strong, binding relationships between the families, and
their interests are in maintaining the marriage relationship and their access to the
children, not necessarily that woman's safety. It's not given first priority (Service
provider).

This reluctance is exacerbated by the lack of housing pathways with many of the housing issues described in Table 5 discussed in the sections that follow. This section highlights additional factors that intersect with the need for accommodation in making the decision to stay or leave.

A significant barrier to leaving is difficulties in accessing finance. This is not just a question of low income but also arises because financial abuse is part of the pattern of domestic and family violence. Informants described many women having little or no money at the time of leaving, as well as difficulty accessing income because her partner controls her Centrelink account. Not having access to funds to travel to a refuge or other safe accommodation can be a substantial deterrent to leaving. This is especially the case in regional and remote areas where accommodation options may be some distance from the family home.

A woman may also have difficulty accessing services such as Centrelink and Territory Housing because her partner's efforts to control her may include hiding her identity and other key documents such as her Basics card, bank cards and documents pertaining to confirmation of 
Aboriginal identity. Consequently, it may be some weeks before she is able to recover these documents to establish an income through Centrelink.

In the process of re-establishing her financial independence, the woman may also discover that she has become responsible for debt that she was unaware of as her partner had previously managed the finances. This 'sexually transmitted debt' often includes, for example, rental arrears, outstanding utility accounts, credit card debt, school fees, and Centrelink debt. 
Figure 2: Barriers to Pathways to Safety

\section{BARRIERS TO PATHWAYS TO SAFETY ...}

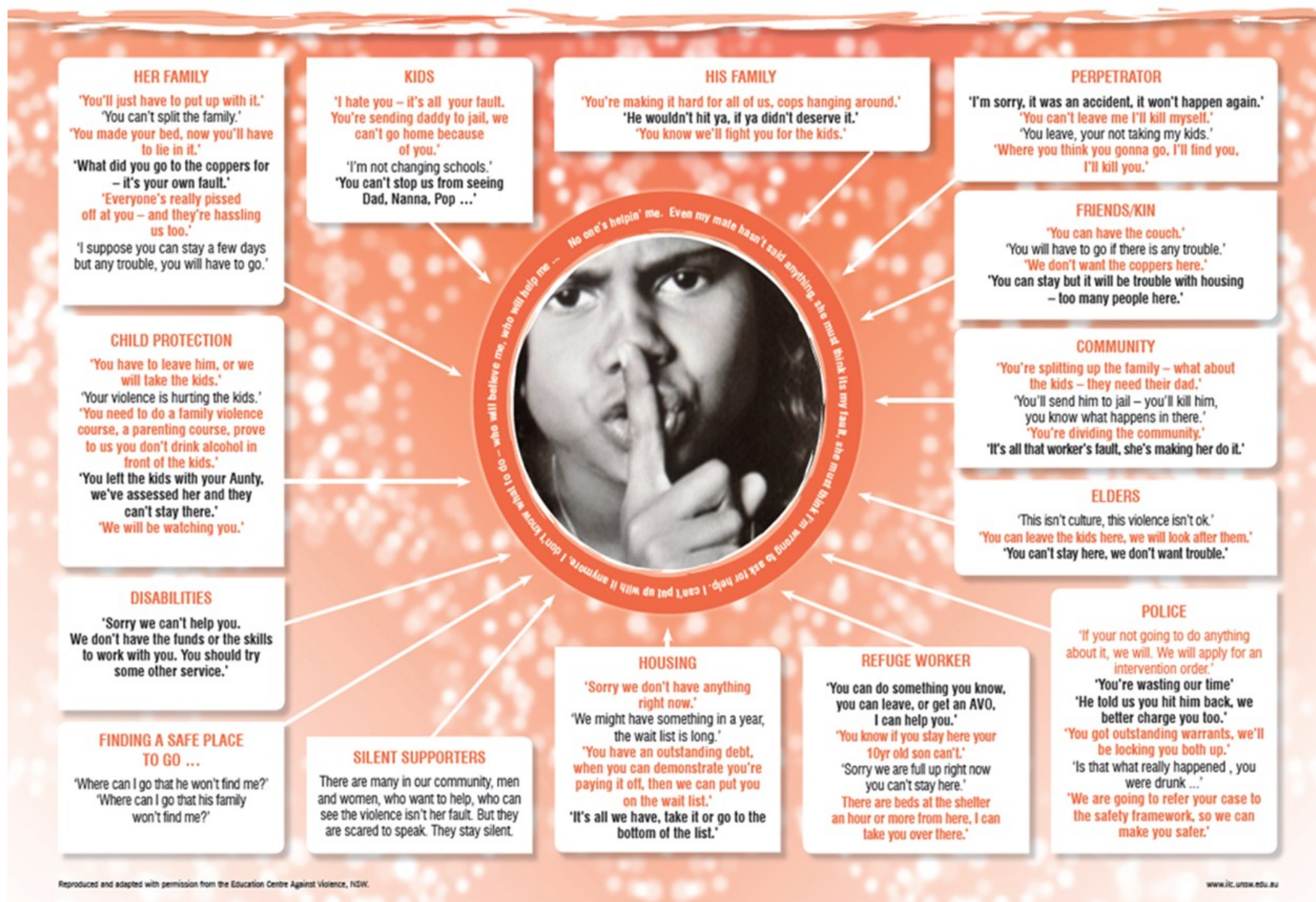

Source: Education Centre Against Violence 
For women with children, the decision to stay or leave is especially complex. As well as weighing up the disruption to schooling and the potential trauma of departure, Indigenous women must also deal with the impact of departure on her wider kinship networks. In many communities there is an expectation that extended kin will be involved with child rearing and in some cases there is a risk of payback from the perpetrator's family, because in leaving she is violating cultural expectations that they should have contact. In one community, cultural expectations were that fathers-and the male side of the family more broadly-should always have access to their children, making the decision to leave especially difficult.

There's the issue of the children and the disruption it causes them. For women there's the obligation to have access to the father. So the needs of the children can be a major barrier. And grandmothers and in-laws can get very volatile because it's their son's children that are being taken away. There's a strong belief that the father has a right to see the children. Both sides have a right to see the children... Often women are left leaving the children behind and that then draws them back into perhaps unsafe situations, or situations where they feel they have no choice (Service provider).

If the woman decides to leave with the children they may be significantly traumatised, and therefore difficult to manage. Child care is a shared responsibility within most Aboriginal communities, so she may find it difficult and challenging to manage the children on her own, particularly if the child's behaviour is violent. It is not unusual for children to be violent in similar ways to the adults in their lives, causing harm to their mothers and their siblings, and to the properties they dwell in. Rather than seeing the damage in the context of the child's response to trauma, the woman may be blamed for providing 'poor parenting'. In these circumstances, where housing services are seeking to recover the costs of repair, they often hold her responsible for the damage.

It is the complexity of this context that makes the decision to stay or to leave exceedingly difficult to navigate for Indigenous women in domestic and family violence situations. The experience of women in our research sites fits with the account given by Cripps, Miller and Yarram (2012: 23) of many Indigenous women continuing to live in violent, unsafe circumstances because this is 'easier than navigating the system in times of crisis. It is too stressful-it's easier to stay'. The lack of options, the costs, and the risks and difficulties of departure from the family home situation leave many women feeling disempowered and unsupported in their efforts to find safety and security for themselves and their children.

\subsection{Housing pathways}

The service user and service provider interviews suggest that there are three main pathways used by Indigenous women to manage situations of domestic and family violence, with the most common being a revolving door between an unsafe home and crisis and transitional services. Far less common, was either relocation away from the perpetrator or remaining within the community, but located at a distance from the perpetrator. While housing access was a substantial barrier to housing pathways, there was also a strong theme of women's reluctance to relocate. They wished for safety and housing security and stability, but if it came at the cost of connection to family and place, it was not seen as a viable option.

\subsubsection{The revolving door-returning to unsafety}

Bottlenecks in crisis and transitional accommodation services mean many Indigenous women are trapped in a revolving door involving short-term departure of a few days, weeks or months from the family home then shifting between different types of accommodation including relatives' homes, safe houses (in remote communities), shelters and temporary accommodation such as caravans and motels. 
Service providers explained that during this time, if the woman has dependent children, she may keep some or all of them with her, or she may place one or more of them, with her own, or her partner's relatives. If the women take out a full or partial domestic violence order (DVO) and the perpetrator is placed in custody or jail for a period she, and any children, may return to the family home. Even if the perpetrator is not incarcerated, she may return home once she feels the threat to her-and her children's safety-has abated. Service providers described this pattern occurring repeatedly for some women. The lack of options beyond crisis accommodation was described by one service user:

\section{My time was up and other families needed to move in, I had no other choice but to go live with my family. At one point I had to go back to my ex because there was no room there (service user).}

This pattern is not always linked to a lack of housing options, but may be a way of managing the perpetrator's substance use. The home may be unsafe during this time and the woman would then remove herself and any children to relatives' homes or crisis accommodation, returning when the risk has passed. Service providers noted that the women would often recognise that 'he's just no good on the grog, or on the drugs' and would make decisions in light of that knowledge.

Domestic and family violence law reforms in recent years have partly responded to this problem by including conditions on DVOs that preclude offenders from approaching the victim or any specified premises within 12 hours of consuming liquor or illicit drugs (ALRC/NSWLRC 2010). This is, however, only useful if the offender moderates their behaviour in accordance with the order, and if they do not that victims can rely on police to enforce the condition.

These situations involve significant risk of harm for victims because even where DVOs are in place the perpetrator may break them, and if they are in police lock-ups or in prison, women are not necessarily advised when they are released. Often many women feel there is nowhere safe to go:

In communities, a woman goes back to our town communities-if the woman goes back to the grandmother, she's got to depend on the strength of the grandmother or grandfather to keep her safe. A lot of the men get released on bail. A lot of the women are scared that they haven't got a safe place to go to (Service provider).

They also feel that there is too much reliance on one system containing the risk, e.g. the justice system through bail or sentencing mechanisms. Yet, the system fails to protect them when the perpetrator is released: first by not notifying the victim ahead of time; second, by not having undertaken sufficient preventative measures in the home in a timely way while the perpetrator is detained; and third, by not providing interventions to the perpetrator while he is detained to challenge his behaviour. These failures result in a revolving door for women where they are locked into circumstances of unsafety. These same women are also offered limited 'after care' by services that could assist them in preventing future violence from occurring. However, as services are overwhelmed with the demand for 'crisis' responses, this 'after care' support is often an afterthought.

\subsubsection{The difficulty of relocation}

Relocation away from family and community was described as being relatively uncommon, partly because of the difficulty in accessing secure housing, and partly because of the strength of ties to community and place, as well as the distances involved.

They very rarely leave ... It is because of this that services have to have an appreciation of the cultural connections and [that] this is where their family is, this is where their support is, and this is really all they know. The nearest place to go if you're 
to go to another place is four hours away. So then they've got problems with transport

and finances and costs (Service provider).

People are also reluctant to leave because even if they are rehoused, they have no experience of living on their own, away from community.

Everybody is so connected here that to break away from that, it's impossible. It's called levee bank syndrome, they've even got a name for it. You go past the levee bank and you can't cope so you come back. ... you can go for a little while, but it sucks you back in (Service provider).

Women from remote communities face particular difficulties in sustaining tenancies in urban environments. But while some may be able to stay with relatives on another remote community, fear that the perpetrator will find them and problems of crowding means their only chance of accessing safe, affordable accommodation is by relocation to a larger population centre. However, the experience of service providers was that few women lasted beyond a few months as they were unused to the tenancy obligations required in urban social housing and had difficulty meeting them. This includes timely rent payments and the need to manage visitors where they breach occupancy regulations or cause problems of good order.

One of the problems is that women come to Darwin and may be offered public housing, however, lateral violence within the home results in property damage so she loses or leaves the home and returns to her unsafe home on community (Service provider).

The disruption to children is also a factor:

They just try not to disrupt the kids as much as possible, especially if they're at school. They don't like picking them up and moving them to another place (Service provider).

Respondents reported that there are a relatively small number of women who relocate at a considerable distance from the family home, sometimes crossing state borders. Given the problems of housing exclusion and the lengthy waiting lists for social housing, even if priority is granted, it is likely that this pathway is likely to involve significant periods of homelessness.

\subsubsection{Remaining in the family home}

The data overwhelmingly suggests that the preference for most women is to remain in the family home, however, it also suggests that current policies are failing in providing safety for women who do this. The reasons for this are two-fold. First, safe at home policies that support home upgrades for women to stay in their home are only available in limited locations. While housing providers reported they are amenable to upgrading properties to support women's safety, they also said that they were constrained by property management budgets. They explained that remoteness makes it particularly difficult, 'sometimes you will have to pay for these quotes to be done, because if the contractor has to travel to quote the job they've got to cover their costs'.

This leads to the second barrier that even if funds were available, the length of time to execute the delivery of upgrades may be prohibitive. It can take several weeks for properties to be assessed, and several more weeks before formal approval is provided and contractors instructed. Service providers felt that there was a need to find ways of minimising the timeframes and were open to using their own staff to take photographs, measurements or do drawings of the women's homes to streamline the process and reduce costs. It is in this context that Safe at Home policies may be more accessible and successful in regional and urban environments as in these locations they can better manage timelines and supports than in remote locations. 


\title{
2.3.4 Indigenous men's needs in the aftermath of domestic and family violence
}

Indigenous men's needs in the aftermath of domestic and family violence were raised several times by service providers and service users. A number of respondents noted that the problem with Safe at Home programs was that for male perpetrators, departure usually meant moving into homelessness, where health and criminalisation risks are high. Given the nature of violence within remote communities, there were some suggestions that in these cases, services need to attend to the housing needs of male perpetrators to reduce the likelihood of their returning to the family home.

There was also a consensus that sending the men to jail was not helping the women in domestic and family violence situations. Indeed it was arguably exacerbating their distressing experiences.

\begin{abstract}
If he goes to jail and he gets out on bail, breaches bail, goes back to jail, goes back, it's a cycle... The problem is that when they're held on bail, they're not eligible being on bail to participate in programs, but the problem is by the time they are sentenced they have served their time on remand and are released without any interventions to address their behaviours. Jail's not going to help.
\end{abstract}

Until someone starts helping the men, our helping the woman can only get to a certain point. We're hitting a whole range of bottlenecks in a whole range of settings that actually keeps us going back to that same cycle... Addressing it goes back to the way you're doing it ... I mean you're effectively making somebody homeless. And then all we're doing is creating a problem for the shelters and it's actually more expensive. And creating a problem for the family, because the family aren't necessarily going to see them living on the street, so yeah, to get rid of one problem you're making another. Unless you change behaviours.

This was an important insight reinforcing observations made previously (see e.g. Chapters 1.3 and 1.5) that the tightly woven cultural and kinship connections in small communities require a holistic response. Thus, in the absence of an equivalent service response for men, providing services to women and children in isolation to the men is, at best, a band-aid solution of limited long-term effectiveness.

\subsection{Policy implications}

This section has highlighted the limited housing pathways available to Indigenous women and children in the aftermath of domestic and family violence. As a consequence, women are caught in a revolving door cycling between an unsafe home, staying with family (typically on couches), or going to crisis and transitional services. This background is useful in understanding the extent to which the term 'choices' is effectively a misnomer since women's housing decisions are so constrained due to limited housing options. In designing policy responses, policy makers need to be alert to this broader context and direct efforts to mitigating the barriers and bottlenecks that inhibit not only the safety of Indigenous women and children, but also their access to long-term housing. They also need to be conscious of the limitations of Safe at Home policies in locations where housing options are limited due to the pressure this places on the perpetrator to return home due to the reality of homelessness, regardless of his legal risk. 


\section{Improving access to safe and appropriate housing}

The access to crisis and transitional housing, particularly in regional and remote areas, is seriously compromised by the limited beds available. With the demand for beds in peak periods, e.g. public and school holidays, the likelihood of women and children being turned away is high. While service providers do their best to find alternative short-term accommodation when and where they can, many women discover that finding a safe place to stay is up to them.

In respect of long-term housing, women and children wishing to be housed separate to their partners were faced with long wait lists for priority housing, typically in excess of a year.

Many women were also delayed access to the priority list until such time as they had demonstrated that they could pay off a housing debt. These debts were typically incurred as a consequence of domestic and family violence and related to unpaid rent and/or damage.

When women were offered long-term housing, there was a sense that they were 'set up to fail' because they were allocated houses in close proximity to their partners which conflicted with child protection orders and put them at risk of losing their children. The houses were sometimes also in 'bad' areas, in poor condition or had maintenance needs beyond their resources. When these conditions were added to the costs of setting up a new home, it became apparent that the burden of domestic and family violence is born most harshly by the women.

Since 2017 the Northern Territory (NT) Department of Housing and Community Development has undertaken significant policy development addressing domestic and family violence and recognising its far-ranging effects. Domestic and family violence is now one of three reasons for priority housing (the others being homelessness and serious medical or social problems), and all staff are advised of mandatory reporting requirements for both domestic and family violence and child abuse. Northern Territory policy initiatives note the vulnerability of Aboriginal women to domestic and family violence and commit to staff training in the area. In addition to notification (to the police for domestic and family violence and DVO breaches, and to family services for child abuse), and referral responsibilities, it identifies the key role of the Department and its housing officers as that of supporting victims to make choices about how to maximise victims' safety. These supports include:

- supporting victims to stay in their present homes where it is safe to do so

- giving consideration to relocation to another property if safety at the current premises is a risk

- reassigning the tenancy.

While supporting documentation (such as a DVO or letter of support from a relevant service) is desirable, it is not mandatory and there is explicit recognition of the difficulties tenants may have in providing this.

In NSW, the Department of Family and Community Services released a housing policy statement in respect of domestic and family violence in October 2018. Consistent with the NT 
policy described above, domestic and family violence is recognised as a significant reason for people seeking assistance from Specialist Homelessness Services in NSW. It places emphasis on the relationship between domestic and family violence and child abuse in particular that domestic and family violence exposure constitutes a form of abuse and that it can compromise a carer's ability to provide a secure stable environment for their child/ren.

It also emphasises that government and non-government agencies have a legal responsibility to protect children at risk of significant harm. The policy differs from the NT in that it does not identify Indigenous women as being a more vulnerable group. The policy is focused on providing options to women in domestic and family violence situations through specific initiatives including:

- Rent Choice Start Safely: a subsidy which provides short to medium-term financial help for women to secure private rental accommodation-something that is unlikely to be of assistance for Indigenous women in the locations we visited

- temporary accommodation for up to 28 days in one year in low-cost hotels, motels, caravan parks, or other similar accommodation

- crisis accommodation through 82 women's refuges across the State

- housing assistance through Housing Pathways providing medium and long-term social housing tenancies.

NSW Housing Policy also recognises domestic and family violence for eligibility for priority housing. They do require supporting documentation and provide a list of possible services/advocates whose support would assist their applications. It is worth also noting, given earlier discussions relating to overcrowding, NSW Housing allocations policy recognises issues with visitors and overcrowding and provides that Aboriginal clients can be matched to properties with one more bedroom than the minimum bedroom entitlement if the client requests. Having said this, it is of course subject to there being sufficient housing stock to meet a family's need. In this respect, several service providers spoke of very large Aboriginal families that struggled with housing they were allocated:

\section{A mum and dad with 7 children allocated a 4-bedroom home, the family regularly had visitors, as well, there were some kids sleeping in the lounge room, there were beds set up in the lounge room, and then mattresses on the floors, that type of thing, the house just wasn't big enough.}

While the examples above demonstrate the developments and significant improvements in housing policy responsiveness to the needs of Aboriginal women in situations of domestic and family violence, there remain many areas where housing services are failing to provide appropriate pathways to safety. The following sections engage with these issues.

\subsection{Access to crisis and transitional housing}

Despite the presence of women's refuges, there were a number of barriers to accessing these. Crisis accommodation was often full, not only due to high demand, but also because insufficient transitional accommodation means there is nowhere for women to move on to. If the crisis service has no bed/s, rental accommodation is rarely an option, so the woman must either find accommodation in a motel or caravan park, return to an unsafe home, or seek accommodation with relatives, creating problems of crowding and possible lack of safety. One service provider reflected on finding a bed in the following terms,

What do you do in that first two weeks of when that woman needs to leave, where do you put her that night? Where do you put her for that week? Where do you put her for 
two weeks? And how do we get her into long-term?-we can get them into motels for 24 to 48 hours. But where do they go after that?

In the event that women are put up at a motel, the service provider noted that being in a small town, it is likely the offender will know where the victim has been placed. Moreover, as observed by participants:

If he [the alleged perpetrator] causes trouble, the motel is unlikely to take her the next time. It's not ideal, but it's a solution.

The refuge is full, the motel won't take you, where do you go?

If there's nowhere, would you go? That's the question. Would you go? Because where do you go?.... She stays, doesn't she.

Even if crisis and transitional accommodation are available, it is not accessible to all women because of exclusion criteria, including:

- Boys over the age of 12 are often excluded from women's shelters. Finding safety for the woman may mean separation from her older, male children and risking their care to another family member or strangers at a time of severe family stress.

- Where a woman may use alcohol or other drugs they are likely unable to access, or remain in, emergency or transitional accommodation since these ban their use.

Our rules are clear-women under the influence are not to come back. We don't know what happens to them, their options are a hostel or staying with families if they plan it ahead. If they don't plan it ahead maybe public spaces or the sobering up shelter (Service provider).

- Women will also be excluded if they do not follow the accommodation rules and/or clash with other residents or workers.

- Family pets are excluded from shelters and transitional accommodation. Dogs in particular are an important source of security in Aboriginal households, that may be particularly important for women in situations of domestic and family violence (Hayes 2017). Family pets may also be used as a way of controlling the woman and making her return home, if the partner threatens to harm them (Service provider).

For women who transition from domestic and family violence shelters or refuges to other temporary accommodation their experiences are equally fraught with problems, as one service provider explained:

Pathways for Indigenous women from community are very limited. One option is Aboriginal Hostels (AHL) they have a banned list to a point that we'll ring up on behalf of someone, and we don't even give a name. They rock up and then they're banned and they're out on the streets again. We try not to use the hostel as our first option because of that reason. And it's really expensive. For the women, what they've expressed to us is it's not a safe place for them, especially if they have children. Some of their comments are 'there's a weird man hanging around'. They don't feel safe. Perpetrators have actually broken in. There's no one on site to call for help. Even how it's varying how they charge...When women are in crisis it takes 5 or 6 days to get their Centrelink-we've been told they can pay cash (while they're waiting for Centrepay). A lady we've been working with previously had been paying cash. No receipts were given. On a Friday afternoon she was told you've only paid up till tomorrow and then you're going to have to move out 'cos you've got no more money. We've been advocating for them-where's your receipts? How come you don't provide receipts so women know where they've paid up to. So it has been quite messy. Sometimes the 
women have Centrepay deductions set up, sometimes they don't, sometimes the hostel takes cash, sometimes they don't, and they don't get receipts (Service Provider).

Other alternative accommodation can include boarding houses. Although the women can stay indefinitely, and they may be affordable for smaller families, they can be inappropriate and expensive for larger ones. Services reported that 'there is nowhere near enough to accommodate the women that we have that need transitional housing'. They also reported that rental assistance was inadequate in these circumstances.

\subsection{Access to long-term housing}

While Indigeneity, homelessness and domestic and family violence are all criteria for inclusion on the priority waiting list, even getting onto the list can be delayed if women lack the necessary identity documentation and confirmation of Aboriginality. This is a significant stumbling block as it delays applications for housing and obtaining income support while new documentation is obtained. Exclusion due to a negative housing history is a further cause of delays due to rental arrears or property damage. Although these commonly occur due to the domestic and family violence itself, the woman's position as the leaseholder can also be used by her partner to control her.

When he isn't on the lease, he does damage, she doesn't want to make a statement because of his threats of further violence, so she wears the debt (Service provider).

Even when accepted onto the priority waiting list, women face a long wait. As one respondent stated: 'DoH wait list is about 7 years unless on Safety Framework and getting priority, priority, priority status'. Others similarly noted:

We could wait 18 months. A lot of the girls will take transfers out of town just to get out of town, but then they're so connected to this community they come back and they're back in the same spot they were in when they left (Service provider).

This is especially the case for women with large families as these properties are less available. Allocations can also be problematic as only one offer is made after which the applicant is removed from the priority list. Offers can be made in any location and respondents described women being offered properties they regard as unacceptable due to being close to the perpetrator or his family, or in neighbourhoods deemed unsafe and inappropriate for women and children traumatised by violence.

One woman explained her situation of having a house and a DVO against her partner, but because he was housed across the street Child Protection deemed the housing situation unsafe and refused to permit the children to be returned. The woman had taken the step of getting a quote for security upgrades to see whether this would facilitate the children being returned, but had not received any reply from Family Services.

A further barrier to obtaining long-term housing is housing debt.

A huge proportion of women have housing debt-about 50 per cent of those presenting. Most who have tenancy have bad history. In this case they're excluded from priority housing. My understanding is having a bad housing history means excluded from priority housing... They either exit our service and that might be a planned service and they tend to go back to where they came from... They're going back to violence. When they do that we try to intervene; we try to see what other options are available for them here in town (Service provider). 
This respondent suggested that 75 to 85 per cent of her clients were in this situation and that it was common for women in the town and on communities.

Some of the women were unaware of the debt until after the relationship dissolved.

He was supposed to be paying rent. Apparently he wasn't... whatever money I was giving him, the rental rebate, Centrelink, he was using it to buy drugs and spending it... and then I was evicted because of the debt (Service user).

Service providers indicated that in these situations, the Department of Housing would expect the women to have prioritised paying down the debt for three months before their application for priority housing can be actioned. As one service provider noted, "housing debt keeps them tied to the situation'. It also contributes to both the crisis and transitional accommodation bottlenecks and exacerbates the housing instability for Indigenous women and children in the aftermath of domestic and family violence.

Service providers also reported that women often felt they were set up to fail whether this be in respect of housing allocations that were inappropriate given their proximity to their ex-partners as was noted earlier, or being allocated houses that may be beyond their capacity with large front/backyards with no one to help them to manage the upkeep.

The house they were in with Department of Housing had a massive back yard and a big front yard and they just weren't able to maintain that. They didn't own a lawn mower, they didn't have a trailer to take all their stuff out to the tip, they don't have a car. And they're not the only ones who are in this position either (Service provider).

Given that they were also often allocated housing in a bad area of town or in a deteriorated condition, the women were often conflicted as to whether to just accept the conditions or to make a fuss knowing that if they did, they would likely have to wait longer for a house.

One of the problems that I see around housing here, there's a house available there, take that and if you don't take that go back to the bottom of the list (Service provider).

There was also evidence that housing tenancy literacy was poor. Areas of confusion included:

- who their landlord was, e.g. Department of Housing or the Aboriginal Housing Office

- their right to public housing, e.g. exclusion from the priority waiting list

- their tenancy rights, e.g. malicious damage

- processes for managing the tenancy, e.g., who to contact for repairs, permitted period of absence, how to escalate requests for repairs.

The combined consequence of both poor property conditions and the lack of housing tenancy literacy meant that the women and children were often living in material conditions worse than when living with their partners. This was further demonstrated by service users and service providers reflecting on the loss of belongings when leaving home, and the difficulty of starting over. It is one thing to successfully obtain a home of one's own, it's another to be able to afford the furniture, bedding, white goods, kitchen utensils, groceries, and all the things needed to make the home a home. While some not-for-profit organisations were available to assist women and children to set up their home, this was piecemeal. The pressure of living in regional and remote areas makes the access and affordability of such goods difficult.

\subsection{Policy implications}

Significant attention to domestic and family violence improvements in housing policy has resulted in changes to policy and increased intervention options for women and children. While 
this has been positive for the most part, our research has highlighted that for Indigenous women and children accessing interventions in their time of need remains challenging. Significant bottlenecks in all of the housing pathways mean that wait times for long-term housing are excessive, typically in excess of a year, leaving Indigenous women and children effectively homeless for lengthy periods of time. When this is coupled with policies that preclude women from being added to the priority housing list because of housing debt that has occurred in the context of domestic and family violence, the likelihood of the women securing safe, stable and affordable long-term housing is significantly compromised, if not jeopardised. There is an urgent need to increase crisis and transitional accommodation and to increase social housing stock. Social housing providers also need to review policies on housing debt in households experiencing domestic and family violence, to ensure that exclusion from the highest priority waiting list does not effectively prevent victims-including children-from establishing a safe home away from the perpetrator. 


\section{$4 \quad$ Improving safety}

Policy reform of the past decade that has emphasised the importance of integrated frameworks for service delivery in response to domestic and family violence have broken down the silos that had characterised domestic and family violence initiatives previously. The domestic and family violence sector now has much improved collaboration, information sharing and accountability with positive outcomes for domestic and family violence victims generally. There are, however, gaps that still require ongoing reform to ensure ongoing service delivery effectiveness. The gaps identified in this research included:

- Ensuring safety meetings are inclusive of all services involved with women and children, e.g. Centrelink, Aboriginal Housing, Aboriginal Medical Services, Mental Health Services. The inclusion of these additional services would ensure wrap-around holistic care that is responsive to women and children's needs. They can also provide essential information to progress applications for income support or housing in a more timely way both at the time of crisis and in the aftermath of violence when ongoing care and support may be required.

- The current format of safety meetings in the jurisdictions of this research do not facilitate victim participation. Given that the women are 'experts of their own lives' enabling their participation is an important step in empowering them to make safe decisions for themselves and their children. The act of participating lets them take control of their situation as opposed to others controlling it for them.

- The need for housing and child protection to work more closely together to ensure that the decisions of each agency do not contradict each other or compromise the safety and long-term wellbeing of Indigenous women and children. Inadequate policy integration between housing and child protection is a significant contributor to the high, and increasing, rates of Indigenous out-ofhome care.

- Training for housing and related services, including family safety program participants, to ensure that they operate free from intentional or unintentional bias and/or racism.

\subsection{Crisis responses: family safety meetings}

Safety frameworks designed to increase service integration and improve the safety of women and children in imminent danger of harm were operating in both case study locations, and appear to have been effective. The establishment of a register of women in immediate danger and the development of plans to ensure their safety at regularly held meetings, together with information-sharing and collaborative working relationships have increased service coordination, improved service responsiveness and accountability, and reduced service duplication. However, there were still a number of gaps and concerns in the response including: inadequate geographical coverage, the extent to which the housing needs of women are 
prioritised alongside the justice response, as well as the unintended consequences for women of information-sharing for child protection issues.

Family safety meetings in New South Wales (Safety Action Meetings) and the Northern Territory (Family Safety Framework) operated in broadly similar ways. Both are located within justice departments and target women identified as in imminent danger of harm or death and have been implemented in select regional towns and cities. Strategies include regular meetings between key government agencies and community sector services, training for all relevant government and non-government staff and a range of primary to tertiary interventions such as:

- implementation and monitoring of domestic violence orders

- assistance for victims to relocate

- fast-tracking of priority housing

- provision of additional home security measures such as window and door locks and safety rooms, phones.

The family safety meetings are typically chaired by police, with other participating agencies including housing and child protection services as well as non-government organisations such as women's shelters who are invited at the discretion of the chair and as appropriate to each case. In the Northern Territory, most referrals are made by NT Police, followed by women's shelters (see Table 6 below). Only 2 per cent of referrals are made by the Department of Housing. 
Table 5: Family Safety Framework NT: Meetings and referrals 2016-2017

\begin{tabular}{|c|c|c|c|c|c|c|c|c|}
\hline & Darwin & Alice Springs & Katherine & Tennant Creek & Nhulunbuy & Yuendumu & $\begin{array}{l}\text { Territory- } \\
\text { wide total }\end{array}$ & \\
\hline \multicolumn{9}{|l|}{ Indicator } \\
\hline Number of meetings held & 25 & 26 & 18 & 24 & 24 & 25 & 142 & \\
\hline Number of referrals received & 81 & 118 & 46 & 53 & 29 & 29 & 356 & \\
\hline Number of referrals accepted & 46 & 27 & 37 & 28 & 17 & 26 & 181 & \\
\hline$\%$ of referrals accepted & $57 \%$ & $23 \%$ & $80 \%$ & $53 \%$ & $59 \%$ & $90 \%$ & $51 \%$ & \\
\hline $\begin{array}{l}\text { Number of re-referrals (previously } \\
\text { accepted) }\end{array}$ & 5 & 32 & 0 & 8 & 0 & 5 & 50 & \\
\hline $\begin{array}{l}\text { Number of female victims } \\
\text { accepted }\end{array}$ & 48 & 27 & 34 & 27 & 16 & 28 & 180 & \\
\hline Number of male victims accepted & 1 & 0 & 3 & 1 & 1 & 1 & 7 & \\
\hline $\begin{array}{l}\text { Number of children attached to } \\
\text { accepted referrals }\end{array}$ & 109 & 13 & 65 & 38 & 43 & 28 & 296 & \\
\hline \multicolumn{8}{|c|}{ Breakdown of referrals received from participating agencies } & $\%$ \\
\hline 1. NTG-NT Police & 18 & 39 & 19 & 19 & 4 & 15 & 114 & $32 \%$ \\
\hline 2. NTG-Health & 10 & 7 & 3 & 15 & 10 & 1 & 46 & $13 \%$ \\
\hline 3. NTG_Housing & 4 & 1 & 1 & 1 & 0 & 0 & 7 & $2 \%$ \\
\hline 4. NTG-Territory Families & 10 & 0 & 4 & 10 & 5 & 0 & 29 & $8 \%$ \\
\hline 5. NTG-Corrections & 0 & 2 & 1 & 0 & 0 & 0 & 3 & $1 \%$ \\
\hline 6. NTG_Education & 0 & 0 & 0 & 0 & 0 & 2 & 2 & $1 \%$ \\
\hline 7. NGO_Women's Shelter & 29 & 47 & 13 & 10 & 7 & 3 & 109 & $30 \%$ \\
\hline
\end{tabular}




\begin{tabular}{|c|c|c|c|c|c|c|c|c|}
\hline $\begin{array}{l}\text { 8. NGO_Aboriginal Health } \\
\text { Organisation }\end{array}$ & 0 & 5 & 2 & 0 & 3 & 1 & 11 & $3 \%$ \\
\hline 9. NGO-Other & 10 & 15 & 0 & 0 & 0 & 0 & 25 & $7 \%$ \\
\hline 10. Centrelink & 1 & 0 & 0 & 0 & 0 & 0 & 1 & $0 \%$ \\
\hline $\begin{array}{l}\text { 11. Information not supplied on } \\
\text { origin of referral }\end{array}$ & 0 & 2 & 3 & 0 & 0 & 7 & 12 & $3 \%$ \\
\hline $\begin{array}{l}\text { Total (may exceed total } \\
\text { received due to joint referrals) }\end{array}$ & 82 & 118 & 46 & 55 & 29 & 29 & 359 & $100 \%$ \\
\hline \multicolumn{9}{|l|}{ Findings } \\
\hline $\begin{array}{l}\text { Average number of accepted } \\
\text { referrals per meeting }\end{array}$ & 2 & 1 & 2 & 1 & Less than 1 & 1 & 1 & \\
\hline $\begin{array}{l}\% \text { of victims previously accepted } \\
\text { onto FSF, re-referred }\end{array}$ & $6 \%$ & $27 \%$ & $0 \%$ & $15 \%$ & $0 \%$ & $17 \%$ & $14 \%$ & \\
\hline $\begin{array}{l}\text { Ratio of female to male victims } \\
\text { (accepted cases only) }\end{array}$ & $48: 1$ & $27: 0$ & $12: 1$ & $27: 1$ & $16: 1$ & $28: 1$ & $26: 1$ & \\
\hline $\begin{array}{l}\text { Ratio of children affected by DV } \\
\text { for every high risk case }\end{array}$ & $3: 1$ & $1: 1$ & $2: 1$ & $2: 1$ & $3: 1$ & $2: 1$ & $2: 1$ & \\
\hline
\end{tabular}


A Northern Territory review of the strategy found that it had improved outcomes for families. Service coordination was also improved, although more work on future initiatives was required (Territory Families 2017: 7). Other key points were:

- the critical role played by local knowledge and regional oversight, but problems with participation due to inadequate resources for administrative support

- there was an unmet need, especially in areas outside of current sites

- the most effective meetings were those where senior staff attended and were able to commit resources in a timely and effective way

- there were barriers to information-sharing partly due to over-reliance on the Risk Assessment Form

- there was a need to improve training for personnel who lacked specialised knowledge and skills in the area

- there were inadequate processes for ensuring victim safety when perpetrators were released from prison

- there was no provision for victim feedback about the framework process and outcomes.

The review also found that where a range of flexible, tailored and safety-focused interventions were in place, victims' safety was not entirely reliant on the incarceration of the offender (Territory Families 2017: 7).

Similar observations were shared by service providers in this research. One of the most significant concerns was that while there is provision to invite additional non-government services to participate in safety meetings, this was an inconsistent practice. Not all services engaged with Indigenous women and children experiencing domestic and family violence were invited to participate in the safety action meetings. Services identified by respondents as being potentially valuable to the safety meetings were Centrelink, Aboriginal Housing Providers, Aboriginal Medical Services, Mental Health Services, Aboriginal Liaison Officers attached to other services whose remit included clients affected by domestic and family violence.

These services could assist in providing a more holistic response and may also be able to advocate on the victim's behalf in ways that others cannot, providing cultural and kinship insights that would foster a more holistic and supportive response. They may also be able to offer practical assistance in breaking down identified bottlenecks, for example, sharing identification information so that victims do not have to wait weeks before they can apply for housing.

The participation of a broader range of services in Family Safety program meetings should also facilitate the establishment of an income for victims. The involvement of services such as Centrelink could potentially result in the relaxation of conditions on looking for work, attending appointments and other activities, as they would be made aware of the circumstances of the victim and could tailor responses accordingly. Indeed some service users and service providers reported on the onerous nature of income support requirements on victims of violence at a time when they are under intense duress. Unless the victim can obtain a medical certificate-which is a hurdle that some women are not in a position to do-Centrelink's income support obligations apply. This takes no account of victims of violence's need for time to manage trauma and the practical tasks involved in establishing safety for themselves and any children.

\subsubsection{Inadequate housing service responses}

The findings suggest that the role of housing in protecting women and children is inadequately acknowledged through family safety meetings. Although there are options for moving women to the top of social housing priority waiting lists and for housing safety upgrades, these were 
reported as rarely applied. The views of a number of service provider respondents was that the information about women on the safety register was shared among participants in ways that potentially placed them at risk of child protection engagement and compromised their access to housing benefits. One service provider observed:

When we get to the (family safety) meeting, the police-the first thing they do is go through the RAP sheet for that person (the victim). We show them the photos of their injuries and this is what they do. Often child protection are sitting there. Housing say they have debt, they've abandoned their residence. It's not relevant to their situation (Service provider).

These observations are important as they speak to how the woman's intersectionality may be framed and judged harshly in these meetings so as not to prioritise support, particularly housing support.

More generally, services suggested that the Department of Housing does not always execute home safety improvements in a timely fashion. As one respondent put it: 'Safe at home would be great if it was being done'.

There were also informants who described timely action by social housing managers in implementing home safety measures, suggesting that the responsiveness of housing services is patchy. Although poor responsiveness needs to be placed in the context of the shortage of social housing supply and limited housing management budgets for housing upgrades, it undermines the principles underpinning family safety frameworks.

\subsubsection{Normalisation of domestic and family violence and its impact on service responses}

Some service providers and service users suggested that serious levels of domestic and family violence within Indigenous communities is normalised within services and this impacts on service delivery. Within all services, including housing, there was a sense that they felt overwhelmed by the level of domestic and family violence-related need in Aboriginal households. There was a sense that Indigenous domestic and family violence is a wicked problem that can't be fixed and that their efforts to address it will never amount to more than band-aid solutions. Their sense of the extent, and intractable nature of the problem was exacerbated by the difficulties Indigenous women and other family members may have in reporting and addressing the violence. The result is a self-fulfilling prophecy in which both the Indigenous women and support services accepted situations that would not be acceptable elsewhere. For example, women turned away from refuges explained they were informed that: 'well we stopped helping you, because you keep going back to the situation' (Service user).

This normalisation of violence amounts to a form of racism. Its roots lie in the construction of Aboriginal people and communities as inherently violent which essentially blames the victim rather than addresses the complex structural intersectional causes that underpin it. As one service provider explained:

'Silly bitch. She shouldn't have married him in the first place...She probably deserves a flogging anyway.' I actually heard a service provider say that to me. I have actually had service providers make those sort of comments (Service provider).

'Just let the bastards kill one another'-that's the perception of a lot of people in this town (Service provider).

Comments of this kind entrench a degree of complacency and resignation among service providers, creating a sense that nothing they do is going to change the situation. 
Women from remote communities have to leave. There is little that is appropriate for them, no support systems here, they end up returning to the violence because there are no options (Service provider).

This results in a toxic situation in which the disempowerment of the woman is matched by the disempowerment of service providers who feel that all their efforts to address the issues are futile.

Indigenous women may never be empowered to say no to the violence, it's no use giving them empowerment, because it may not be culturally appropriate (Service provider).

These attitudes contribute to low levels of reporting and a tendency to manage violence within the family, with attendant risks to women and children, as well as pressure to remain in unsafe situations. Rather than fully engaging with the possibilities for supporting the woman, it creates a climate of hopelessness, thereby limiting consideration of options and services provided.

\subsubsection{Unintended consequences of information-sharing for child protection notifications}

In their response to the National Plan to reduce Violence Against Women and their Children, many jurisdictions have enacted legislation to facilitate improvements in information sharing. ${ }^{3}$ While, on paper, this appears to be a positive move to secure safety and support for victims, there are also potential unintended consequences, particularly for victims whose experiences are complex due to intersectionality.

Service providers and service users described circumstances of victims referred to family safety meetings, who up until that moment had not been involved with child protection services. However, as child protection agencies are part of the framework, they learn about notifiable issues including the domestic and family violence and precarious housing arrangements-a point also noted in Tasmanian research (Hinton 2018). Given that this knowledge comes in the context of structural barriers to housing access that are well beyond the control of the women, this is a significant concern. There is an inherent contradiction between policies that seek to reduce the removal of Indigenous children and ones that heighten these risks without also providing additional strategies to address this.

\subsubsection{The Safe House program}

The Safe House program was originally established as part of the Northern Territory Emergency Response (NTER) and specifically targeted remote Indigenous communities. At the time, many remote communities had no crisis accommodation, no DV services and, in smaller communities, no police services. The program was designed to fill this gap by providing women and children at risk of physical harm from other family members, with safe emergency accommodation. However, delays in establishment, the use of shipping containers for construction, community distrust due to the context of the NTER and lack of community consultation, meant that they were initially under-utilised (Gosford 2008). The speed of the NTER meant they were also not always established in the area of highest need.

The views of respondents on how well the safe houses operated are mixed. They offer crisis accommodation in communities that often lack any other form of housing support and where the alternative is the homes of relatives, often creating problems of crowding. Respondents pointed out that the way the safe houses are actually used is distinct from the women's shelter model in which immediate shelter is provided as a first step on the women's pathway to economic and

\footnotetext{
${ }^{3}$ See for example, Crimes (Domestic and Personal Violence) Act 2007 (NSW), Part 13A.
} 
social independence from her abusive male partner. Instead they are mostly used as a form of respite in situations where the home may be unsafe because the perpetrator is drinking and the woman can stay away with her children until the risk of violence has passed.

There were also concerns that safe houses were essentially a band-aid solution and given how costly they are to run, initiatives developed in greater consultation with communities might be more effective.

They've arisen out of the only imagined response that many people saw, because they understood there was these women's shelters and women's refuge, so what we need is a safe house out here. It's much easier to imagine a bricks and mortar response than imagining something, a kind of system of responses and engagement and integration. What would that look like, you know? It's really hard, it's not tangible. Then, I think, it's also, part of the pressure expectation has come from non-Aboriginal people and non-community people, such as health workers, health clinic workers and police, who, for them, it's really hard living in a remote community and dealing with these problems, and if you have a safe house we can put these women in that's just going to solve it all (Service provider).

Very few safe houses are integrated with other services and most provide only limited-or noongoing support or referral, so they do nothing to address the underlying problems and provide no long-term solutions. There are also concerns that they provide only limited safety. The absence of medium-term accommodation and the limit of a three-day period means women are sometimes forced to return to an unsafe situation (Wadeye Safe House 2014). The employment of local women means that tribal differences make it difficult for some families to use them, and even where they are available, they may not be accessible because staff are not employed fulltime.

There are also concerns for the safety of staff and clients. The women who staff the safe houses can be subject to intimidation from members of their community and, because it is difficult to keep their location secret, the residents may also not feel safe, with fear of payback and violence from perpetrators. As one respondent put it:

Women in the communities, some have safe houses, but those are only as strong as the community can make them (Service provider).

\subsection{Policy implications}

The focus of more recent State/Territory policy initiatives designed to improve safety for women and children through safety frameworks including the prioritisation of high risk cases to safety meetings involving key service providers has had beneficial outcomes. The improved coordination, responsiveness and accountability of services through these frameworks has the potential to dramatically improve the safety and housing stability of women and children in the aftermath of domestic and family violence. There are, however, gaps in the current framework that policy makers need to resolve to ensure equality of access for all women, but especially Indigenous women and children. This chapter highlighted that specific attention is needed to ensure that Indigenous women's experiences of violence are not normalised and accepted or excused. Service delivery to this group needs to be of the same standard offered to other groups. The women should not be judged or provided with substandard care under a misguided guise of 'cultural appropriateness'. This necessitates building stronger relationships between Indigenous and non-Indigenous service providers as well as specific training in areas including but not limited to, cultural competency, cultural safety, and recognising unconscious bias in service provision. 
There is also scope for housing policy to more appropriately target the needs of women in remote communities. The experience of safe houses suggests there is a need for new intervention models that recognise the women's attachment to country and kin, and the practical difficulties of establishing a life away from these. The complexity of their situation requires holistic responses that can empower women to work through these issues, while also ensuring their safety. 


\section{Service integration: domestic and family violence, housing and child protection}

There is a significant misalignment between housing and child protection services that makes finding safety without risking the removal of children by child protection services a substantial concern for many Indigenous women.

In many cases Indigenous women in situations of domestic and family violence face a situation of triple victimisation, through family violence, removal of children, and homelessness. These findings are supported by both AHURI research and research on child protection in Tasmania in which the lack of housing pathways is a major contributor to repeated child removals (Flanagan, Blunden et al. 2019; Hinton 2018). While there is scope for improved service coordination, it is hard to see how this negative intersection can be addressed without also addressing the shortage of affordable accommodation that is its root cause.

\subsection{Domestic and family violence, housing and risk}

The intersection between social housing, domestic and family violence and child protection policies place the woman in an untenable position where, whether she leaves or stays, she risks losing the children. Mandatory reporting of both DV and child abuse, as well as duty of care mean the involvement of child protection services is likely if the home environment is violent or housing conditions are insecure.

Under current legislation, inadequate or insecure housing or unsafe homes, including being exposed to domestic and family violence, are reasons for the removal of children (Funston, Herring and ACMAG 2016: 54; AFVPLS Victoria 2014). Because the child's needs are prioritised, child protection officers expect mothers to secure their child's safety by reporting violence and implementing full DVOs. This action demonstrates to child protection that mothers can, and are, acting protectively, placing the needs of their children above that of their partners. For women who choose not to take out an order the risk of children being removed increases. Given the lack of affordable housing, this demand is problematic for all low-income women, but it is especially problematic for low-income Indigenous women because of their situational and cultural context:

- The woman may have a close bond with the perpetrator and feel he is only violent when he's drunk:

He's a great father but he's just no good on the grog, or on the drugs or something like that, that's where the Police, if the incident happened when they've been on the grog or on the drugs, that's when they will look at adding that condition there to a DVO.

At least half of them will tell you, nine times out of ten, it's when he's on alcohol or drug-affected that the violence flares up. The rest of the time he'll take the kids to school and make them lunch, get their breakfast.

- Reporting violates kinship obligations that she should support her husband.

- Extreme rates of Indigenous incarceration make her reluctant to take action which will result in her partner's imprisonment. 
- The expectation that a full order be taken out violates cultural and kinship expectations that the father and his family have contact with his children.

In the context of housing scarcity, the woman has two alternatives. One is to leave but to manage the problem of housing insecurity by placing the children with relatives.

\section{Sometimes the women come without the children. They leave them on community with the family... A high proportion of the women are living in his home with his family (so the children remain with the perpetrator's family) (Service provider).}

However, this may still be problematic given levels of crowding in many Indigenous homes, and the potential for child protection services to have concerns about the appropriateness of the placement. The other option is to leave with the children, but with access to housing so uncertain, this is equally risky from a child protection perspective. The women are therefore in a 'no-win' situation, placing them in an impossible situation. The role of housing in creating this is well understood by participants. One woman explained that her children grew up seeing all the violence and they would say: 'Mum, why do we have to run all the time? Why can't we just stop home?' I said, 'It's not safe at home. If we had a more safe, more secure house there, I wouldn't have to leave' (Service user).

\subsection{Child removal and reunification}

If children are removed, the lack of stable, safe and affordable housing also has a substantial negative impact on the potential for reunification. One respondent explained the difficulty she had in getting her children back after they had been removed because child protection deemed the housing situation unsafe because she had a DVO against her partner who was housed across the street. Since finding alternative accommodation was unrealistic she was seeking to get security upgrades but did not know if the Department of Housing would agree to this.

Another woman (service user) was told that to get her children back she had to prove that she was: no longer using drugs or alcohol; no longer involved with her ex-partner; she had to have suitable housing for her and the children, and she also had to have a job. She told us that she had achieved all of the requirements except finding a house. She had been on a public housing waiting list for two years after leaving her partner. She had tried to obtain private rental accommodation only to be turned away at the Real Estate Office when they realised she was Aboriginal. When we asked if she was sure that that was the reason, she said: 'They told me it was taken already, but it is still up on the internet as available, what other reason could there be?'. Her last interaction with child protection about getting her children back broke her heart: the child protection worker told her 'your children are settled now, perhaps you should just move and start a new life somewhere else'. She said: 'They are my kids, I'm their mother, I want to be there for them, I just need a house' (Service user).

Women also reported that child protection workers would offer to assist them to get 'a new house, get the children set up, get us somewhere safer away from all the trouble' but that those promises never materialised: '[A]fter they took the children off me, that's when I had to go out and figure it all out myself' (Service user). This is a clear example of there being no after-care available for the mother once her children were removed, reinforcing her isolation and despair.

Where child removal services identify the removal as being long-term (typically 1-2 years) or permanent, housing policy is to reallocate the parent to a smaller property if their current property is larger than they now require. Since child protection services will not permit reunification to take place unless the parent can provide adequate housing, including sufficient bedrooms, this is a major barrier to reunification. Although housing service respondents explained that these cases were allocated to priority waiting lists, the views of other service 
provider respondents were that wait times were often so lengthy as to make reunification difficult.

If she loses the kids, she loses the house absolutely. I have heard mums say, 'How am I going to do reunification? I have got no house for you to bring them because you took the kids off me and I lost the house' that's a huge problem.

Housing move them onto a one-bedroom if the kids are on a long-term order, child protection say 'you have got to have a house for the kids to come home to. She's in a 'catch 22'.

She's never going to get the kids back. Then the women lose hope, then they go and partner up with someone and the domestic violence just starts again. You know housing is just so fundamental to this (Service provider).

\subsection{Collateral consequences of child removal for domestic and family violence victims}

The removal of children by child protection services has a direct impact on homelessness because of its financial, emotional and psychological impact. It results in a loss of income, especially if they move from Parenting Payments to Newstart. Several respondents highlighted the way women who have had their children removed face the demand by child protection for them to be employed before the children can be returned. This is matched by income support requirements that welfare recipients should be in the labour force. This policy applies regardless of location and the availability of employment, the skills of the woman or the context in which she requires income support. The women are also afforded little support to navigate these demands.

One service user explained:

Basically, if you're a jobseeker here and you're female it's arts, crafts, sewing, floral arrangements and childcare that they're basically given the options for these days. Not everybody wants to do that (Service user).

From the perspective of one service provider, this approach did little to support women to establish independence in the wake of domestic and family violence:

That's not necessarily building her up to be self empowered, to make financial decisions for herself, to be able to have an inner strength... (Service provider).

For most women, the removal of children results in a drop in income that makes it difficult to maintain rental payments, creating a further barrier to accessing private rental markets.

These financial difficulties are compounded by the sense of failure, hopelessness and disempowerment that follows child removal. Some Northern Territory service providers explained that this was sometimes associated with increased substance use and consequent public space dwelling. This pattern is supported by research on 'long grassers' (public space dwellers living in parklands in Northern Territory cities) which shows that one of the factors influencing some Indigenous women to live in a public space is the shame associated with losing their children (Holmes and McRae-Williams 2008). Hinton's research also describes one of the collateral consequences of child removal as an increase in substance use issues, mental issues and housing instability (Hinton 2018: 36).

With the kids gone, one woman also commented that she had asked housing to get her a transfer to a new house and, contrary to the experience described above (of women moved to 
smaller accommodation), she felt trapped in a house which was beyond her capacity to maintain:

[B]ecause l'm one person in a four-bedroom house, they said I cannot get a transfer. They said if I want to move, I have to go private housing or do a house swap with somebody. I told them it's just one person in the house, the rent and everything it's too much. I can't get help of Centrelink or nothing now because I have a job. I don't receive Centrelink payments anymore. It's just been hell. The last year l've just been stuck in the same house and nothing's changed (Service user).

This reflection reaffirms the findings of Hinton (2018) described earlier. Women in these situations are experiencing 'collateral consequences' potentially leading to a 'perfect storm' where their lives are spiralling out of control through a lack of support and recognition that their financial and familial circumstances have dramatically changed and that their housing arrangements need to be modified accordingly.

\subsection{Policy implications}

This section highlighted the intersections in domestic and family violence, housing, child protection and income support policies and the consequences when policies are not aligned. It demonstrated that the decisions made by housing impact directly on whether women will be able to keep custody of their children. In the event that children have already been removed, housing decisions can impact directly on the possibilities for reunification. Given the historical and intergenerational experiences of child removal in Indigenous families and communities, it is important that policy makers consider how housing decisions impact on matters of Indigenous child protection. The removal of children has collateral consequences (Hinton 2018) that may exacerbate financial insecurity, housing insecurity, substance use and risks to health and mental health. At the heart of the policy disconnect between child protection and housing is the lack of affordable housing. Beyond this, policy makers should actively resolve conflicts in policy and practice so as to ensure women and children in domestic and family violence situations are supported and safely accommodated together as a family unit. 
This research found that Indigenous women and children have very limited housing pathways to choose from in the aftermath of domestic and family violence. Acute shortages in crisis, transitional and long-term housing, particularly in regional and remote locations, mean that Indigenous women and children are routinely turned away from refuges and safe houses because they are at capacity. In these circumstances they become trapped in a revolving door, seeking shelter with family/friends or returning to an unsafe home.

While the Australian and state/territory governments around Australia have improved responses to domestic and family violence through law reforms and integrated service systems, they still tend to adopt a one-size-fits-all approach that fails to respond to the intersectionality of Indigenous women's and children's experiences of domestic and family violence. This failure results in significant unintended consequences for Indigenous women and children, the most serious being the very real risk that their children will be removed.

To mitigate against this outcome, policy development is required, concentrating on increasing the availability of beds in crisis and transitional housing and, where possible, increasing housing stock for the long-term accommodation needs of Indigenous women and children.

Other areas for policy development should examine the development of local placebased, co-designed, holistic care services, that centre upon empowering Indigenous women.

\subsection{The problem: housing pathways for Indigenous women and children in the aftermath of domestic and family violence}

This research explored how housing and other service responses need to be improved to meet the needs of Aboriginal individuals and families in the aftermath of domestic and family violence. Through the lens of housing pathways and intersectionality the research highlights the particular vulnerabilities of Aboriginal women and children as they engage with government departments and services to secure accommodation and safety. The findings give voice to the barriers that Indigenous women face in exercising agency, and highlight areas where policy and practice may be improved to better support and accommodate their housing needs. The sections that follow articulate these actions.

\subsection{Analysis of current practice and responses}

Our research suggests that national policies on domestic and family violence are making headway in some respects. There is some evidence that service integration has been strengthened and that this has seen improvements in the management of domestic and family violence cases deemed at high risk and in imminent danger of harm or death, where information sharing between agencies has improved the prioritisation of housing and other services to assist victims. Improved integration has also resulted in increased training opportunities for 
frontline and other relevant government and community sector personnel, and in greater service provider awareness of the importance of this issue and its implications for the safety of women and children, including among housing staff. Policies on the removal of perpetrators from the lease and the subsequent transfer of lease to the victim can also be effective, especially in major cities and towns, enabling women to remain in their home, with support.

However, there are unintended consequences of these developments, most notably the increased surveillance of domestic and family violence victims by child protection and a subsequent heightened risk of child removal. While this is an issue for all women experiencing domestic and family violence, it is especially acute for Indigenous women where the intersectional nature of their disadvantage and intergenerational experiences with child removal compounds their vulnerability. This firstly heightens the risks that children will be removed to out-of-home care, and secondly heightens the difficulty of establishing a safe, stable home for reunification to be realised.

A key theme running through the findings is the extent to which policy objectives of women's empowerment to make informed choices are failing. The primary reason for this is the lack of housing options at every point of the housing pathway. Rather than having genuine housing options in managing domestic and family violence, women are instead caught in a revolving door in which she cycles between an unsafe home, to family or friends couches, to crisis services, and back to an unsafe home. Bottlenecks in crisis and transitional services, exclusion from mainstream housing markets and inadequate social housing supply result in women having few options but to return to the family home, despite the danger to herself and her children, and despite the risk that this will result in the removal of her children.

This cycle is exacerbated by additional factors, most notably the normalisation of violence that impacts on service responses, and the lack of culturally appropriate service provision. There was a sense that although services are committed to reducing the impact of Indigenous domestic and family violence and may be deeply concerned about the issue, they also feel overwhelmed by the extent of the problem. Our findings suggest this can shift perceptions about what is an acceptable service response in ways that negatively impact on Indigenous women and children. Despite the best efforts of many services, rather than empowering Indigenous women to establish safety for themselves and their children, there are aspects of current approaches that reinforce and entrench a sense of powerlessness. Women are often left feeling that service responses to domestic and family violence are being done to them rather than with them, and that their options are limited.

It is in these circumstances, that women will be considering their options and making decisions, trying to balance everyone's needs and expectations including those of their children, families, partner and service providers. These decisions may conflict with how policy and/or services measure risk and safety. This is not to say that the women are not alert to the significance and consequences of risk, but that they know their situation better than professionals coming in and out of their lives on an ad hoc basis. There is a need for policy responses to review risk assessment tools whose efficacy has already been questioned (Ringland 2018) and to calibrate them so that they are more attuned to the cultural and kinship strengths of Indigenous women rather than focusing purely on potential deficits.

What we heard overwhelmingly through our research was that Indigenous women and children carry the burden of managing risk and safety in the aftermath of domestic and family violence. They are the ones negotiating alternative accommodation, dealing with the intrusiveness and surveillance of integrated domestic and family violence frameworks, and managing the risks of losing children to child protection. A key finding was that Indigenous women prioritise their connections to family and place in their decision-making and are clear that interventions that come at the expense of those connections are not a viable long-term option. This is particularly 
relevant to remote communities, where a combination of housing exclusion and cultural expectations makes departing family and community extremely difficult.

This is one of the reasons why long-term safety requires holistic services that address the needs of all family members. As one service provider explained:

\section{Until someone starts helping the men, our helping the woman can only get to a certain point (Service provider).}

There is therefore a need to develop policy and intervention options that cater to both the victim and the alleged offender, focused on providing crisis accommodation and other housing pathways as appropriate, so that neither party becomes vulnerable to homelessness. Support services for men are also critically needed to enable them to reflect on and change behaviours.

\subsubsection{Lack of housing choices at every stage of the housing pathway}

A key finding of this research is that while the capacity of both Indigenous and non-Indigenous women to escape domestic and family violence is severely compromised due to the severity of the lack of housing choices, the situation for Indigenous women and children is significantly worse. While both groups have a high dependence on social housing, this dependence is far higher for Indigenous women because of the extent to which they are excluded from the private rental market. The cluster of factors that comprise the intersectionality of Indigenous womenpoverty, gender, ethnicity and, in some cases, regional or remote residence-means that, for many, social housing is the only option. Yet these women rely on a domestic and family violence system that prioritises their needs in principle, but which fails them because it fails to prioritise housing need. Consequently, rather than having housing 'choices', the women's typical pathways are:

- staying with others (e.g. couch surfing)

- staying in a refuge

- staying at home.

Significant and chronic bottlenecks in the homelessness system are matched by the bottlenecks in available permanent accommodation through public and/or community housing, so that those women seeking to be housed separate from the domestic and family violence perpetrator are typically waiting at least a year, more often in excess of a year, before suitable accommodation becomes available. These bottlenecks in regional and remote Australia are so acute that for many Indigenous women and children attempting to access them in times of crisis, many will likely be either turned away, be forced to find safety elsewhere, or will try to manage at home. There is therefore a need to increase accommodation options to cater for the increasing demand for domestic and family violence services.

\subsubsection{Service integration}

In Australia it is now accepted that service integration is the gold standard for responding to domestic and family violence, and certainly its status as a first line response in high risk domestic and family violence cases has been prioritised by the Australian and all state and territory governments. It has had a real and visible impact for those women experiencing domestic and family violence as it has reduced the siloed nature of services, improved information sharing, reduced duplication, and improved accountability of services to each other and to the women. However, there are significant gaps in service integration that could potentially compromise the safety and housing circumstances of women. 


\section{Housing and child protection}

Throughout this report the impact of poor service coordination between housing and child protection policy and service delivery on the high, and increasing, rate of Indigenous childremoval has been emphasised. A shortage of crisis and transitional accommodation and the lack of affordable housing is the root of the problem. Addressing this deeply dysfunctional policy outcome therefore necessitates the development of programs that specifically target the housing needs of Indigenous women in the aftermath of domestic and family violence. Given the collateral damage of child removal on both parents and children in terms of homelessness, incarceration and compromised physical and mental health, such an investment should make a substantial contribution to closing the gap targets.

\section{Family safety framework meetings}

The integrated models involving safety meetings were valued by service providers and women alike as in these meetings 'people do what they say they are going to do' with outcomes that improve women's safety and housing. There were, however, a number of areas requiring improvement:

- Inadequate attention is paid to the role of housing in ensuring women's safety. Consideration should be given to requiring social housing services to offer Indigenous women at imminent danger of serious injury or death, options for safe, affordable accommodation, regardless of their housing history. Given the severe resource constraints on housing services, this may require Australian Government funding to provide more accommodation as well as increased resources for retrofitting homes with increased safety measures. This is especially important in locations where options for safety are severely constrained and services are limited, as is the case in many remote communities.

- There is scope to extend the services included in meetings especially women's services and Centrelink, with the goal of removing barriers to women's safety in areas such as housing and income support.

- Policy makers also need to consider expanding the safety framework so that it can be offered to a broader range of women who are not deemed high risk since levels of risk are fluid and a situation may move rapidly from low to high risk.

- For the same reason, consideration should be given to criteria for removal from the list, especially the practice of removal if the perpetrator is incarcerated since this may not be for long, and there is currently no commitment to ensuring that women are informed and protected once he is released.

- Despite the fact that domestic violence and Indigenous policy settings stress the empowerment of Indigenous people, family safety frameworks do not address this. Current approaches need to ensure that Indigenous women participate in meetings and that their voices are included and heard in the decision-making process.

- While family safety framework meetings have improved service integration for women identified as in imminent danger of serious injury or death, for those that do not meet the current threshold there is no urgency or demand to push the 'less risk' cases through an integrated framework or approach. This is not to say that the individual workers are not effective in achieving outcomes for these women, but rather there is no obligation on other agencies to work as collaboratively or to the same level of accountability as they would in the high risk cases. Given that Indigenous women face considerable barriers to reporting violence, including the normalisation and minimisation of their experiences, each service engagement should be an experience that maximises their safety and ensures access to secure accommodation. The safety framework model enables this for 'high risk' cases. As Indigenous women experience significant barriers in accessing timely domestic and family 
violence support, it may be worth using the safety framework model to prioritise their cases irrespective of their risk categorisation, recognising that to delay the provision of support potentially puts her at risk of further violence but also not trusting domestic and family violence services to assist her the next time she is in a crisis situation.

\section{Addressing policy and service delivery gaps}

Gaps in service integration mean that the housing support required to establish safety are not necessarily available or accessible in timely ways. This is especially the case for women in regional and remote locations where crisis services are limited or non-existent, and programs such as Safe at home, and the family safety framework, are unavailable. There is potential for policy makers to work more closely with front line services to determine how the delivery of such programs in regional and remote areas can be more effectively streamlined to reduce costs and time delays.

\subsubsection{Holistic service provision}

While the national domestic violence policy framework has had many beneficial results, our research suggests it is insufficiently calibrated to the needs of Aboriginal women and the distinct characteristics of domestic and family violence experienced by Aboriginal people. This is particularly the case for women living in remote communities, but it is also true for women in larger population centres. At every level, policy and practice fail to take adequate account of the intersectionality of their experience, in particular the social, cultural, economic and geographical context of Aboriginal women, resulting in their pathways to safety being limited.

A significant theme in this research was the strength of kinship ties and kinship obligations, and how this impacts on the choices Aboriginal women make in situations of domestic and family violence. The need for culturally appropriate holistic services that are able to cater to all family members and to the diversity of circumstances and needs that they present with, was reiterated throughout this research. Such services enable women to make informed decisions about whether to remain in the home and or on community, it is essential therefore that they exist, and that they are funded on an ongoing basis.

Indigenous women in domestic and family violence situations need to have choice in the access of services. Women already make decisions on which services to access based on prior experiences, trust, community knowledge, relationships and anonymity. It should not be assumed that Indigenous women will preference an Indigenous service over a mainstream service, but rather they make these decisions balancing a range of risks and expectations. In designing policy responses for Indigenous women and children, policy makers should be alert to the diversity of options available and be sure not to unintentionally limit them.

Holistic services should also include some consideration for the needs of male perpetrators. Supporting men into alternative accommodation would reduce the risks to women and the potential that they will move into homelessness or possible incarceration. The development of healing programs targeting behavioural change in men and boys should also be an essential component of the policy mix. There is growing evidence that Aboriginal males have suffered significant and unique damage to their spiritual wellbeing, with the result that their very conception of what it means to be a male has been shattered (Arney and Westby 2012). The idea that men should be empowered to take control of their lives, and re-adjust towards a positive view of masculinity within a mutually supportive environment based around social learning principles is powerful. Although more research is needed, programs designed to address Indigenous family violence have shown promise especially when they are characterised by strong community involvement and a holistic approach (Closing the Gap Clearinghouse 2016). 


\subsubsection{Consequences of inadequate policy}

Throughout this report we have identified the need for national and state/territory-based policy to improve policy integration and improvements in service coordination in the areas of domestic and family violence, child protection and housing to ensure effective responses to the needs of Indigenous women and children. Despite recent efforts to improve this, it remains the case that Indigenous women continue to feel the harshness of policies that are poorly calibrated to the impact of their intersectionality. This contributes to the failure of current efforts to close the gap in key areas of Indigenous health and wellbeing. In December 2018, COAG committed to forming a genuine formal partnership with Indigenous peoples in Australia to finalise the Closing the Gap Refresh and to provide a forum for ongoing engagement throughout the implementation of the new agenda. A Partnership Agreement between COAG and Aboriginal and Torres Strait Islander Peak Organisations also came into effect in March 2019 and a Joint Council on Closing the Gap has been established to provide oversight of the implementation and monitoring of the Refresh. Draft targets have been announced in seven priority areas.

The areas most relevant to this research are 'Families, Children and Youth' and 'Housing'. The overarching goals for these areas focus on safe families and households, housed in secure appropriate, affordable housing. They aim to achieve this primarily by addressing overcrowding. The refresh is also embracing intersectionality as it considers cross-system priorities, but there is currently little detail as to how this will operate.

This research suggests that the focus on crowding is too narrow and misses many of the other significant and potentially more critical housing issues faced by Indigenous women and children in the aftermath of domestic and family violence. In particular, it pays no attention to the impact of housing shortages on the safety of Indigenous women and children and the risks of collateral damage (Hinton 2018) in other policy areas. There is an urgent need for the Australian Government to address this within the refresh by bringing the issue of housing into the consideration of targets and strategies relating to Indigenous domestic and family violence.

It is important to recognise that an inadequate policy response to housing needs associated with Indigenous domestic and family violence contributes substantially to other areas of Indigenous disadvantage:

- It is a major contributor to tenancy failure, both directly through the impact of domestic and family violence on arrears, property damage, property abandonment and indirectly through the impact of couch surfing and consequent destabilisation of the host's tenancy.

- It is a major contributor to homelessness because of the lack of housing options, both couch surfing and public space dwelling.

- It is a major contributor to the removal of children and is a barrier to reunification.

- It is a major contributor to criminalisation that goes well beyond the criminal justice response to the perpetrator of domestic and family violence. Homelessness may result in warnings, fines and incarceration, especially where women self-medicate through drinking or the use of drugs. The financial impact may also result in problems with the law. The impacts on children include being unable to go home due to violence and therefore becoming vulnerable to involvement in juvenile justice or child protection systems.

This research would argue that failure to provide appropriate, safe and affordable housing to women and children escaping domestic and family violence directly and substantially contributes to intergenerational disadvantage of Aboriginal women and children. It is therefore incumbent upon policy makers to carefully consider how and in what ways averting these outcomes can be achieved. 


\subsection{Supporting and empowering Indigenous women and families through culturally appropriate policy and service delivery}

The key finding from this study is that domestic violence policy frameworks will fail Indigenous women and children so long as the extreme shortfalls in crisis, transitional and long-term housing remain unaddressed. In responding to this need, the research has also demonstrated the economic, social and cultural context in which Indigenous domestic and family violence occurs also requires housing and other services that are culturally appropriate. The demands and expectations of kin, the relationship to country and the extent of exclusion from private rental markets are just some examples of why this is necessary.

There is a substantial literature that speaks to the power and transformative actions of local, place-based community initiatives, often inspired and led by Indigenous women who have successfully responded to the complexities and nuances of domestic and family violence (Cripps and Davis 2012; HREOC 2008). This is not to say that there is no place for government and/or non-government services engaging in this space, as is recognised in the literature (Cripps and Davis 2012; HREOC 2008).

Services and government departments engaged with Indigenous women experiencing domestic and family violence should be encouraged to use a strengths-based model that recognises and respects that the women are the 'experts of their own lives'. By using this model they would be giving the women the autonomy and empowerment they need to make decisions that embrace and respond to their intersectionality. This exercise in Indigenous self-determination will likely result in increased empowerment because the voices of women are heard, and their needs are identified on their terms. It is incumbent then for government and services to be willing to adapt their policies and practices to the expressed needs of Indigenous women both individually and collectively. The latter is particularly important given the structural and institutional issues identified throughout this report that have impeded Indigenous women's self determination.

The application of a strengths-based model extends beyond the individual woman experiencing domestic and family violence as it will likely create opportunities more broadly within families and the Indigenous community for the exchange of ideas on domestic and family violence solutions, building the capacities of individuals, families and communities through domestic and family violence education and training opportunities; and opening access to wider policy and practice solutions beyond the existing well-meaning but often fragmented intersectoral policy and practice approaches to domestic and family violence that struggle to meet the safety and accommodation needs of Indigenous women and children.

This change in approach requires training and support for the domestic and family violence sector and other service providers engaged in working with women and children experiencing domestic and family violence. This is necessary to shift discourses that normalise the violence experienced by Aboriginal communities and to challenge conscious and unconscious racialised bias towards race. It would be useful for this training to be developed locally so that it builds partnerships with local leaders/communities/women in the development of place-based responses.

In stressing the need for Indigenous-led solutions, the underlying fundamental issue remains one of a lack of housing pathways. The most effective way to improve the safety of Indigenous women and children in the aftermath of domestic and family violence is to fix the bottlenecks in the homelessness system, and to improve access to affordable, stable and safe housing.

Beyond this, this report identifies a range of policy options for reducing barriers to accessing housing, such as more flexible policies in relation to housing debt, and increased responsiveness to the needs of Indigenous women on safety framework registers. 
Finally, policy makers need to consider the long-term sustainability and continuity of housing and domestic and family violence services in Indigenous communities. It is widely recognised that domestic and family violence is not something that can be completely ameliorated from any community, yet the sector continues to be funded on a short-term basis, with contracts rarely being more than 1-2 years (Flatau, et al 2016). This not only undermines trust in services, it also substantially reduces their capacity and effectiveness.

\subsection{Final thoughts}

This research has demonstrated the extent to which housing is implicated in the difficulties that Indigenous women face in finding safety in the aftermath of domestic and family violence. As well as direct, physical violence, these difficulties add to the burden of harm, state intrusion and intervention they face, especially in relation to homelessness and child removal. The extensive nature of their intersectionality creates an increased need for housing and domestic violence and child protection sectors to work more closely together.

While our research stressed supply issues in crisis, transition and long-term housing that are unlikely to be fixed quickly given cost and resource implications, we also identify many ways in which policy and services may better integrate to empower Indigenous women to make housing choices that ensure their safety. While efforts to reduce bottlenecks should be prioritised, both Indigenous and non-Indigenous services are working on innovative policy solutions that can support Indigenous women and children to be safe and accommodated. Rather than perpetuating historical policy discourses that Indigenous domestic and family violence is a wicked problem incapable of solution, policy directions need to explore how, through proper consultative, co-designed and integrated initiatives, opportunities for improving housing options that support the safety of Indigenous women and children is both necessary and possible. 


\section{References}

(ABS) Australian Bureau of Statistics (2010) The health and welfare of Australia's Aboriginal and Torres Strait Islander peoples, October 2010, cat. No. 4704.0, ABS.

(ABS) Australian Bureau of Statistics (2016) Census 2016 QuickStats, accessed 20 September 2018, https://www.abs.gov.au/websitedbs/D3310114.nsf/Home/2016\%20QuickStats.

(ABS) Australian Bureau of Statistics (2017) Personal safety, Australia, 2016, cat. no. 4906.0, ABS, Canberra, http://www.abs.gov.au/ausstats/abs@.nsf/mf/4906.0.

(AIHW) Australian Institute of Health and Welfare (2014) Housing outcomes for groups vulnerable to homelessness, AlHW, Canberra.

(AlHW) Australian Institute of Health and Welfare (2016) Family violence prevention programs in Indigenous communities, Resource sheet no. 37, Closing the Gap Clearinghouse, https://www.aihw.gov.au/getmedia/c0e5bdde-e9c4-4a1f-808e-256191835cde/ctgcrs37.pdf.aspx?inline=true.

(AIHW) Australian Institute of Health and Welfare (2018a) Family, domestic and sexual violence Australia, 2018, AlHW, Canberra.

(AlHW) Australian Institute of Health and Welfare (2018b) Specialist Homelessness Services Annual Report 2017-18, AlHW, Canberra, https://www.aihw.gov.au/reports/homelessnessservices/specialist-homelessness-services-2017-18/contents/client-groups-ofinterest/clients-who-have-experienced-domestic-and-family-violence.

(AlHW) Australian Institute of Health and Welfare (2019a) Aboriginal and Torres Strait Islander people: a focus report on housing and homelessness, AlHW, Canberra.

(AlHW) Australian Institute of Health and Welfare (2019b) Child protection Australia: 2017-18, Child welfare series no.70. cat. no. CWS 65, AlHW, Canberra.

(AFVPLS) Aboriginal Family Violence Prevention and Legal Service Victoria (2014) Submission no. 73 to the Inquiry into Domestic Violence in Australia, Parliament of Australia, Canberra, https://www.aph.gov.au/Parliamentary Business/Committees/Senate/Finance and Public Administration/Domestic Violence/Submissions.

(ALRC/NSWLRC) Australian Law Reform Commission and NSW Law ReformCommission (2010) Family violence_a national legal response, Final Report, ALRC report no. 114, NSWLRC report no. 128, ALRC and NSWLRC, Sydney.

Arney, F. and Westby, M. (2012). Men's places literature review. Darwin, NT: Child Protection Research Program, Menzies School of Health Research.

Blagg, H., Bluett-Boyd, N. and Williams, E. (2015) Innovative models in addressing violence against Indigenous women: state of knowledge paper, ANROWS, Sydney, https://www.anrows.org.au/publication/innovative-models-in-addressing-violence-againstindigenous-women-state-of-knowledge-paper/.

(BOSCAR) Bureau of Crime Statistics and Research (2018) Domestic violence statistics for NSW, https://www.bocsar.nsw.gov.au/Pages/bocsar pages/Domestic-Violence.aspx.

Bryant, W. and Bricknell, S. (2017) Homicide in Australia 2012-13 to 2013-14: National homicide monitoring program report, Australian Institute of Criminology (AIC), Canberra. 
Bullen, J. (2015) 'Governing homelessness: the discursive and institutional construction of homelessness in Australia', Housing, Theory and Society, vol. 32, no. 2: 218-239.

Casey, S., Entwistle, P. and Entwistle, D. (2012) A needs analysis of alcohol related service delivery in the Katherine region: an Aboriginal community controlled approach, Centre for Remote Health, Charles Darwin University.

Clapham, D. (2002) 'Housing pathways: a post modern analytical framework', Housing, Theory and Society, vol. 19, no. 2: 57-68.

Clapham, D. (2003) 'Pathways approaches to homelessness research', Journal of Community \& Applied Social Psychology, vol. 13: 119-127.

Clapham, D. (2005) The Meaning of Housing: A Pathways Approach, The Policy Press, Bristol.

Clapham, D., Mackie, P., Orford, S., Thomas, I. and Buckley, K. (2014) 'The housing pathways of young people in the UK', Environment and Planning A, vol. 46, no. 8: 2016-2031.

Closing the Gap Clearinghouse (AlHW and AIFS) (2016) Family violence prevention programs in Indigenous communities, Resource sheet no. 37, the Closing the Gap Clearinghouse, AlHW, Canberra and AIFS, Melbourne.

(COAG) Council of Australian Governments (2009), National Integrated Strategy for Closing the Gap in Indigenous Disadvantage, 2 July 2009, https://www.coag.gov.au/meetingoutcomes/coag-meeting-communiqu\%C3\%A9-2-july-2009.

(COAG) Council of Australian Governments (2011) National plan to reduce violence against women and their children: including the first three-year action plan, Council of Australian Governments, https://www.dss.gov.au/women/programs-services/reducing-violence/thenational-plan-to-reduce-violence-against-women-and-their-children-2010-2022.

Courtney, M., McMurtry, S. and Zinn, A. (2004) 'Housing problems experienced by recipients of child welfare services', Child Welfare, vol. 83: 393-422.

Cripps, K. (2007) 'Indigenous family violence: from emergency measures to committed longterm action', Australian Indigenous Law Review, vol. 11, no. 2: 6-18.

Cripps, K. and McGlade, H. (2008) 'Indigenous family violence and sexual abuse: considering pathways forward', Journal of Family Studies, vol. 2, no. 8: 240-253.

Cripps, K. (2012) 'Indigenous children's 'Best Interests' at the crossroads: citizenship rights, Indigenous mothers and child protection authorities', International Journal of Critical Indigenous Studies, vol. 5, no. 2: 25-35.

Cripps, K. and Davis, M. (2012) Communities working to reduce Indigenous family violence, Research Brief No. 12, Indigenous Justice Clearinghouse, http://www.indigenousjustice.gov.au/briefs/brief012.pdf.

Cripps, K., Miller, L. and Yarram, D. (2012) Resistance and renewal: building and supporting community-led partnership initiatives responding to family violence in Indigenous communities in Victoria, Community Report, Indigenous Law Centre, UNSW, Sydney.

Cripps, K. and Adams, M. (2014) 'Chapter 23: Indigenous family violence: pathways forward', in R. Walker, P. Dudgeon, and H. Milroy (eds.), Working Together: Aboriginal and Torres Strait Islander Mental Health and Wellbeing Principles and Practice, Australian Government Department of the Prime Minister and Cabinet, Telethon Kids Institute/Kulunga Aboriginal Research Development Unit, Perth: 399-416. 
Culhane, J., Webb, D., Grim, S., Metraux, S. and Culhane, D.P. (2003) 'Prevalence of child welfare services involvement among homeless and low-income mothers: a five year birth cohort study', Journal of Sociology and Social Welfare, vol. 56: 79-95.

Daoud, N., Matheson, F, I., Pedersen, C., Hamilton-Wright, S., Minh, A., Zhang, J. and O'Campo, P. (2016) 'Pathways and trajectories linking housing instability and poor health among low-income women experiencing intimate partner violence (IPV): toward a conceptual framework', Women \& Health, vol. 56, no. 2: 208-225.

Davis, M. (2012) 'Aboriginal women: the right to self determination', Australian Indigenous Law Review, vol. 16, no. 1: 78-88.

Domestic Violence NSW (n.d.) Good practice guidelines for the domestic and family violence sector in NSW, https://www.dvnsw.org.au/work/resources/good-practice-guidelines-for-thensw-domestic and family violence-sector/.

Fidler, L. (2018) In limbo. Exploring income and housing barriers for reunifying Tasmanian families, Anglicare, Hobart, Tasmania.

Fien, J.and Charlesworth, E. (2012) 'Why isn't it solved? Factors affecting improvements in housing outcomes in remote Indigenous communities in Australia', Habitat International, vol. 36: 20-25.

Flanagan, K., Blunden, H., Valentine, K. and Henriette, J. (2019) Housing outcomes after domestic and family violence, AHURI Final Report 311, Australian Housing and Urban Research Institute Limited, Melbourne, http://www.ahuri.edu.au/research/final-reports/311, doi: 10.18408/ahuri-4116101.

Flatau, P., Zaretzky, K., Wood, L. and Miscenko, D. (2016) The financing, delivery and effectiveness of programs to reduce homelessness, AHURI Final Report 270, Australian Housing and Urban Research Institute, Melbourne, https://www.ahuri.edu.au/research/final-reports/270, doi:10.18408/ahuri-8209101.

Fopp, R. (2009) 'Metaphors in homelessness discourse and research: exploring "pathways", "careers" and "safety nets"', Housing, Theory and Society, vol. 26, no. 4: 271-291.

Funston, L., Herring, S. and ACMAG (2016) 'When will the stolen generations end? A qualitative critical exploration of 51 contemporary 'child protection' practices in Aboriginal and Torres Strait Islander Communities', Sexual Abuse in Australia and New Zealand, vol. 7, no. 1: $51-58$.

Gosford, R. (2008) 'Safe houses in the NT—a \$21 million "massive stuff-up", Crikey, 12 November, https://blogs.crikey.com.au/northern/2008/11/12/safe-houses-in-the-nt-a-21million-massive-stuff-up.

Habibis, D., Birdsall-Jones, C., Dunbar, T., Scrimgeour, M., Taylor, E. and Nethercote, M. (2011) Improving housing responses to Indigenous patterns of temporary mobility, AHURI Final Report No. 162, Australian Housing and Urban Research Institute Limited, Melbourne, https://www.ahuri.edu.au/research/final-reports/162.

Habibis, D., Memmott, P., Phillips, R., Go-Sam, C., Keys, C. and Moran, P. (2013) Housing conditionality, Indigenous lifeworlds and housing policy outcomes: towards a model for culturally sensitive housing provision, AHURI Positioning Paper No. 212, Australian Housing and Urban Research Institute Limited, Melbourne. 
Hayes, H. (2017) 'In the remote Aboriginal community of Yuendumu, dogs are not just pets', ABC News, 17 October 2017, https://www.abc.net.au/news/2017-10-08/dogs-not-just-petsin-remote-aboriginal-community-of-yuendumu/8998016.

Hinton, T. (2018) Breaking the Cycle: Supporting Tasmanian parents to prevent recurrent child removals, Anglicare Tasmania, Hobart.

Holmes, C. and McRae-Williams, E. (2008) An investigation into the influx of Indigenous 'visitors' to Darwin's Long Grass from remote NT communities-Phase 2. Being undesirable: law, health and life in Darwin's Long Grass, Larrakia Nation Aboriginal Corporation Research Division and funded by the National Drug Law Enforcement Research Fund, an initiative of the National Drug Strategy.

(HREOC) Aboriginal and Torres Strait Islander Social Justice Commissioner (2006) Ending family violence and abuse in Aboriginal and Torres Strait Islander communities: key issues, Human Rights and Equal Opportunity Commission (HREOC), Sydney, https://www.humanrights.gov.au/our-work/aboriginal-and-torres-strait-islander-socialustice/publications/ending-family-violence.

(HREOC) Aboriginal and Torres Strait Islander Social Justice Commissioner (2007) Social Justice Report 2006, Human Rights and Equal Opportunity Commission (HREOC), Sydney, https://www.humanrights.gov.au/sites/default/files/content/social justice/sj report/sjreport0 6/pdf/sir full.pdf.

(HREOC) Aboriginal and Torres Strait Islander Social Justice Commissioner (2008) Social Justice Report 2007, Human Rights and Equal Opportunity Commission (HREOC), Sydney, https://www.humanrights.gov.au/our-work/aboriginal-and-torres-strait-islandersocial-justice/publications/social-justice-report-2.

(HREOC) Aboriginal and Torres Strait Islander Social Justice Commissioner (2011) Social Justice Report 2011, Human Rights and Equal Opportunity Commission (HREOC), Sydney, https://www.humanrights.gov.au/our-work/aboriginal-and-torres-strait-islandersocial-justice/publications/social-justice-report-3.

Johnson, M. (2008) A Typology of Violence: Intimate Terrorism, Violent Resistance, and Situational Couple Violence, University Press of New England, NH, Lebanon.

Kerr, J. (2017) 'A descriptive analysis of the characteristics, seriousness and frequency of Aboriginal intimate partner violence in the Northern Territory, Australia: a strategy for targeting high harm cases', M App Crim, Cambridge University, Cambridge.

Long, S., Memmott, P., Seelig, T. (2007) An audit and review of Australian Indigenous housing research, AHURI Final Report No. 102, Australian Housing and Urban Research Institute Limited, Melbourne, https://www.ahuri.edu.au/research/final-reports/102.

Luna, E. (1999) 'Indigenous women, domestic violence and self determination', Indigenous Law Bulletin, vol. 4, no. 25: 8-10.

McDermott, Q. (2012) 'Four Corners: a matter of life and death', ABC, 30 July 2012, https://www.abc.net.au/4corners/a-matter-of-life-and-death/4180146.

Milligan, V., Phillips, R., Easthope, H., Liu, E. and Memmott, P. (2011) Urban social housing for Aboriginal people and Torres Strait Islanders: respecting culture and adapting services, AHURI Final Report No. 172, Australian Housing and Urban Research Institute Limited, Melbourne, https://www.ahuri.edu.au/research/final-reports/172. 
Moran, M., Memmott, P., Nash, D., Birdsall-Jones, C., Fantin, S., Phillips, R. and Habibis, D. (2016) Indigenous lifeworlds, conditionality and housing outcomes, AHURI Final Report No. 260, Australian Housing and Urban Research Institute Limited, Melbourne, https://www.ahuri.edu.au/research/final-reports/260.

(NAAJA) North Australian Aboriginal Justice Agency Northern Territory (2016) Housing issues paper and response to the housing strategy consultation draft, http://www.naaja.org.au/wpcontent/uploads/2014/05/NAAJA-submission-NTG-Housing-Strategy-2016.pdf.

Nancarrow, H. (2016) Legal responses to intimate partner violence: gendered aspirations and racialised bodies, PhD Thesis, School of Criminology and Criminal Justice, Faculty of Arts, Education and Law, Griffith University.

Northern Territory Government (2014) Northern Territory Government submission to the Senate Inquiry into Domestic Violence in Australia, Senate Standing Committee on Finance and Public Administration, Parliament of Australia, Inquiry into domestic violence in Australia, Submission 158, November 2014, https://www.aph.gov.au/Parliamentary Business/Committees/Senate/Finance and Public Administration/Domestic Violence/Submissions?main 0 content 1 RadGrid1ChangePa ge $=7 \quad 20$.

Northern Territory Government (2018) Safe, respected and free from violence: domestic, family and sexual violence reduction framework 2018-2028, https://territoryfamilies.nt.gov.au/ data/assets/pdf file/0006/464775/Domestic,-Familyand-Sexual-Violence-Reduction-Framework.pdf.

Northern Territory Government (n.d.) Safety is everyone's right, https://territoryfamilies.nt.gov.au/ data/assets/pdf file/0003/513633/Safety-is-EveryonesRight-Overview.pdf.

NSW Government (2014) Program guidelines for Staying Home Leaving Violence program, Vulnerable Children and Families Directorate, NSW FACS, Sydney.

NSW Government (2016) Domestic and family violence Blueprint for Reform 2016-2021, NSW Ministry of Health, Sydney.

NSW Government (2018) Domestic and family violence: NSW Department of Family and Community Services (FACS) Housing Policy Statement, NSW FACS, Sydney.

Office of Women's Policy (n.d.) Policy framework for Northern Territory women 2015-2020, Northern Territory Government, https://dhcd.nt.gov.au/ data/assets/pdf file/0005/261518/policy-framework-for-ntwomen.pdf.

(PMC) Commonwealth of Australia, Department of the Prime Minister and Cabinet (2017) Closing the Gap Prime Minister's Report 2017, http://closingthegap.pmc.gov.au.

Productivity Commission (2014) Overcoming Indigenous disadvantage key indicators 2014 report, http://www.pc.gov.au/research/ongoing/overcoming-indigenous-disadvantage/2014.

Productivity Commission (2016) Overcoming Indigenous disadvantage: key indicators 2016, https://www.pc.gov.au/research/ongoing/overcoming-indigenous-disadvantage/2016.

Ringland, C. (2018) The Domestic Violence Safety Assessment Tool (DVSAT) and intimate partner repeat victimisation, Crime and Justice Bulletin, No. 213, Bureau of Crime Statistics and Research, Sydney. 
Roberts, D., Fuller, D., Bradley, H., Hugo, G., Coffee, N. and Gollan, S. (2006) The emerging housing needs of Indigenous South Australians, AHURI Final Report, Australian Housing and Urban Research Institute, Melbourne.

SCRGSP (Steering Committee for the Review of Government Service Provision) (2014), Report on Government Services 2014, Productivity Commission, Canberra.

SCRGSP (Steering Committee for the Review of Government Service Provision) (2016), Report on Government Services 2016, Productivity Commission, Canberra.

SCRGSP (Steering Committee for the Review of Government Service Provision) (2017), Report on Government Services 2017, Productivity Commission, Canberra.

Sanders, W. (2009). Ideology, evidence and competing principles in Australian Indigenous affairs: From Brough to Rudd via Pearson and the NTER, Centre for Aboriginal Economic and Political Research Discussion Paper No. 289/2009 (Canberra: Australian National University).

Senserrick, T., Lyford, M., Hinchcliff, R., Boufous, S., Clapham, K. F., Torr, S. and Ivers, R. (2012) Evaluation of the Bourke Alcohol Action Plan: Final Report, The George Institute for Global Health, University of Sydney, Sydney.

Sharp, N. (2008) 'What's yours is mine': the different forms of economic abuse and its impacts on women and children experiencing domestic violence, Refuge, United Kingdom.

Southwell, J. (2002) Family violence and homelessness: removing the perpetrator from the home, Discussion Paper No. 3, Domestic Violence and Incest Resource Centre, Melbourne.

Spinney, A. and Blandy, S. (2011) Homelessness prevention for women and children who have experienced domestic and family violence: innovations in policy and practice, AHURI Positioning Paper No. 140, Australian Housing and Urban Research Institute Limited, Melbourne, https://www.ahuri.edu.au/research/position-papers/140.

Spinney, A. (2012) Home and safe? Policy and practice innovations to prevent women and children who have experienced domestic and family violence from becoming homeless, AHURI Final Report No. 196, Australian Housing and Urban Research Institute Limited, Melbourne, https://www.ahuri.edu.au/research/final-reports/196.

Spinney, A., Habibis, D. and McNelis, S. (2016) Safe and sound? How funding mix affects homelessness support for Indigenous Australians, AHURI Final Report No. 272, Australian Housing and Urban Research Institute Limited, Melbourne, https://www.ahuri.edu.au/research/final-reports/272.

Stracey, M. (2003) 'Sustaining Indigenous tenants at risk of eviction: A Victorian homelessness strategy pilot', Parity, vol. 16, no. 9: 5-6.

Territory Families (2017) Review of the Family Safety Framework Northern Territory 20162017, Northern Territory Government, https://territoryfamilies.nt.gov.au/domesticviolence/review-of-the-family-safety-framework-2016-17.

Valentine, K. and Breckenridge, J. (2016) 'Responses to family and domestic violence: supporting women?', Griffith Law Review, vol. 25, no. 1: 30-44.

Victorian Commission for Children and Young People (2016) 'Always was, always will be Koori children': Systemic inquiry into services provided to Aboriginal children and young people 
in out-of home care in Victoria, Victorian Commission for Children and Young People, Melbourne, Victoria.

Wadeye Safe House (2014) Submission no. 107 to the Inquiry into Domestic Violence in Australia, Parliament of Australia, Canberra,

https://www.aph.gov.au/Parliamentary Business/Committees/Senate/Finance and Public Administration/Domestic Violence/Submissions.

Wiesel, I., Easthope, H., Liu, E., Judd, B. and Hunter, E. (2012) Pathways into and within social housing, AHURI Final Report No. 186, Australian Housing and Urban Research Institute Limited, Melbourne,

https://www.ahuri.edu.au/ data/assets/pdf file/0006/2040/AHURI Final Report No186 Pathways into and within social housing.pdf.

Wild, R. and Anderson, P. (2007) 'Little children are sacred' Board of Inquiry into the protection of Aboriginal children from sexual abuse, Northern Territory Government, Darwin. 


\section{AHURI Research Centres}

AHURI Research Centre-Curtin University

AHURI Research Centre-RMIT University

AHURI Research Centre-Swinburne University of Technology

AHURI Research Centre-The University of Adelaide

AHURI Research Centre-The University of New South Wales

AHURI Research Centre-The University of South Australia

AHURI Research Centre-The University of Sydney

AHURI Research Centre-University of Tasmania

\section{Australian Housing and Urban Research Institute}

Level 12

460 Bourke Street

Melbourne Victoria 3000

T +61396602300

E information@ahuri.edu.au

ahuri.edu.au

ACN 090448918

twitter.com/AHURI_Research

f facebook.com/AHURI.AUS

in evid.in/AHURI_Linkedln 